\title{
Oxidative Phosphorylation-an Update on a New, Essential Target Space for Drug Discovery in Mycobacterium tuberculosis
}

\author{
Caroline Shi-Yan Foo ${ }^{1}$, Kevin Pethe ${ }^{2, *}$ and Andréanne Lupien ${ }^{3,4, *}$ \\ 1 Laboratory of Virology and Chemotherapy, Rega Institute, Leuven 3000, Belgium; caroline.foo@kuleuven.be \\ 2 Lee Kong Chian School of Medicine and School of Biological Sciences, Nanyang Technological University, \\ Singapore 636921, Singapore \\ 3 Infectious Diseases and Immunity in Global Health Program, Research Institute of the McGill University \\ Health Centre, Montreal, QC H4A 3J1, Canada \\ 4 McGill International TB Centre, Montreal, QC H4A 3J1, Canada \\ * Correspondence: kevin.pethe@ntu.edu.sg (K.P.); andreanne.lupien@mail.mcgill.ca (A.L.)
}

Received: 29 February 2020; Accepted: 24 March 2020; Published: 29 March 2020

\begin{abstract}
New drugs with new mechanisms of action are urgently required to tackle the global tuberculosis epidemic. Following the FDA-approval of the ATP synthase inhibitor bedaquiline (Sirturo ${ }^{\circledR}$ ), energy metabolism has become the subject of intense focus as a novel pathway to exploit for tuberculosis drug development. This enthusiasm stems from the fact that oxidative phosphorylation (OxPhos) and the maintenance of the transmembrane electrochemical gradient are essential for the viability of replicating and non-replicating Mycobacterium tuberculosis ( $M . t b)$, the etiological agent of human tuberculosis (TB). Therefore, new drugs targeting this pathway have the potential to shorten TB treatment, which is one of the major goals of TB drug discovery. This review summarises the latest and key findings regarding the OxPhos pathway in $M$. $t b$ and provides an overview of the inhibitors targeting various components. We also discuss the potential of new regimens containing these inhibitors, the flexibility of this pathway and, consequently, the complexity in targeting it. Lastly, we discuss opportunities and future directions of this drug target space.
\end{abstract}

Keywords: Mycobacterium tuberculosis; energy metabolism; electron transport chain; oxidative phosphorylation; tuberculosis; drug discovery; bedaquiline; Q203

\section{Introduction}

Tuberculosis (TB) continues to have a significant global burden by remaining one of the top ten killers worldwide and the leading cause of death due to a single infectious agent [1]. The causative agent, Mycobacterium tuberculosis ( $M$. $t b$ ), has evolved to adapt to a range of environmental stresses encountered during infection, giving rise to sub-populations of bacteria in heterogenous metabolic states, from actively replicating, to slow-growing, and dormant, non-replicating bacteria [2]. Conventional anti-TB drugs primarily target processes required for cell growth and replication, and are less efficacious against non-replicating bacteria, resulting in lengthy treatments in both drug-susceptible (DS-TB) and drug-resistant TB (DR-TB) cases [1,3]. In addition, current treatments for DR-TB are associated with low cure rates and toxicity [4-6]. Therefore, the successful elimination of the disease requires the development of new anti-TB drugs ideally active against non-replicating bacterial subpopulations and drug-resistant strains.

A new target space that has garnered increasing interest is energy metabolism, and in particular, the oxidative phosphorylation (OxPhos) pathway. The first clinical validation of this pathway as a mycobacterial drug target occurred in 2012, with the FDA approval of bedaquiline (BDQ) for treating 
DR-TB by targeting the mycobacterial $\mathrm{F}_{1} \mathrm{~F}_{0}$ ATP synthase [7]. This has been followed by the regulatory approvals of nitroimidazoles delamanid (Deltyba; DEL) and pretomanid (PA-824) [8,9], with the demonstration of PA-824 killing non-replicating $M$. $t b$ by inhibition of the respiratory cytochromes through the release of nitric oxide (NO) [10]. Additionally, Telacebec (Q203), which is currently in Phase 2 clinical trials, targets the primary terminal oxidase cytochrome bcc-aa3 complex (Cyt-bcc-aa3) of $M . t b[11,12]$. Altogether, this highlights the vulnerability of energy metabolism in this pathogen and the sensitivity of components of the OxPhos pathway to specific chemical inhibition. Despite the high degree of conservation of this pathway between prokaryotes and eukaryotes, the ability to specifically target mycobacterial components without affecting the human mitochondrial counterparts has alleviated safety concerns, opening up a new and attractive target space for drug discovery.

From a biological viewpoint, this pathway is promising as a drug target space for several reasons. Whereas substrate-level phosphorylation can provide a sufficient amount of energy for replication in many bacteria, $M$. $t b$ is dependent on the more energetically-efficient OxPhos to sustain growth [13-15]. This is probably linked to the absence of a NADH-dependent lactate dehydrogenase in mycobacteria, which would limit efficient fermentation [16,17]. During the OxPhos process, electrons are transferred from electron donors of central metabolism to oxygen through the electron transport chain (ETC). The energy released in this transfer is conserved by the proton-pumping components of the ETC, generating an electrochemical gradient in the form of a proton motive force (PMF). This stored energy is then mined through the ATP synthase as protons flow back down the gradient to yield ATP. Since a sustained PMF and ATP replenishment are essential even for the viability of non-replicating M. $t b$ [18-21], it is believed that inhibition of the OxPhos pathway is an effective strategy to eradicate non-replicating subpopulations, thereby shortening future treatment durations. Moreover, since drug efflux pumps are energy-dependent in actively transporting drugs out of the bacterial cell, perturbation of the PMF and ATP levels may interfere with their function as well [13]. It has been demonstrated that efflux pump activities play a significant role in drug susceptibility of $M . t b$ [22-27] and, therefore, perturbation of the OxPhos pathway may indirectly aid in overcoming issues of efflux-pump mediated drug resistance.

In light of these significant interests in targeting energy metabolism in mycobacteria, this review aims to (1) summarise key findings of the main components comprising the OxPhos pathway of $M$. $t b$, (2) provide an overview of validated inhibitors of this pathway which are either in the discovery stage, in clinical development, or have been approved, (3) discuss the potential of new regimens containing these inhibitors, (4) highlight possible concerns in targeting this pathway, and (5) discuss future opportunities and directions for drug development in this space.

\section{Main Components of the OxPhos Pathway in M. $t b$}

The ETC of $M . t b$ comprises nine primary dehydrogenases, which fuel the respiratory chain as electron donors, and four-terminal oxidoreductases, which catalyse the transfer of electrons to terminal electron acceptors such as oxygen [14]. The lipoquinone, menaquinone (MK), serves as the intermediary electron carrier between the primary dehydrogenases and terminal oxidoreductases. In the following section, we summarise the main components of the pathway against which inhibitors have been discovered and those which are potentially suitable drug targets. In particular, this includes the NADH dehydrogenases, succinate dehydrogenase, the MK biosynthesis pathway, the two terminal oxidases, ATP synthase and the PMF (Figure 1). 


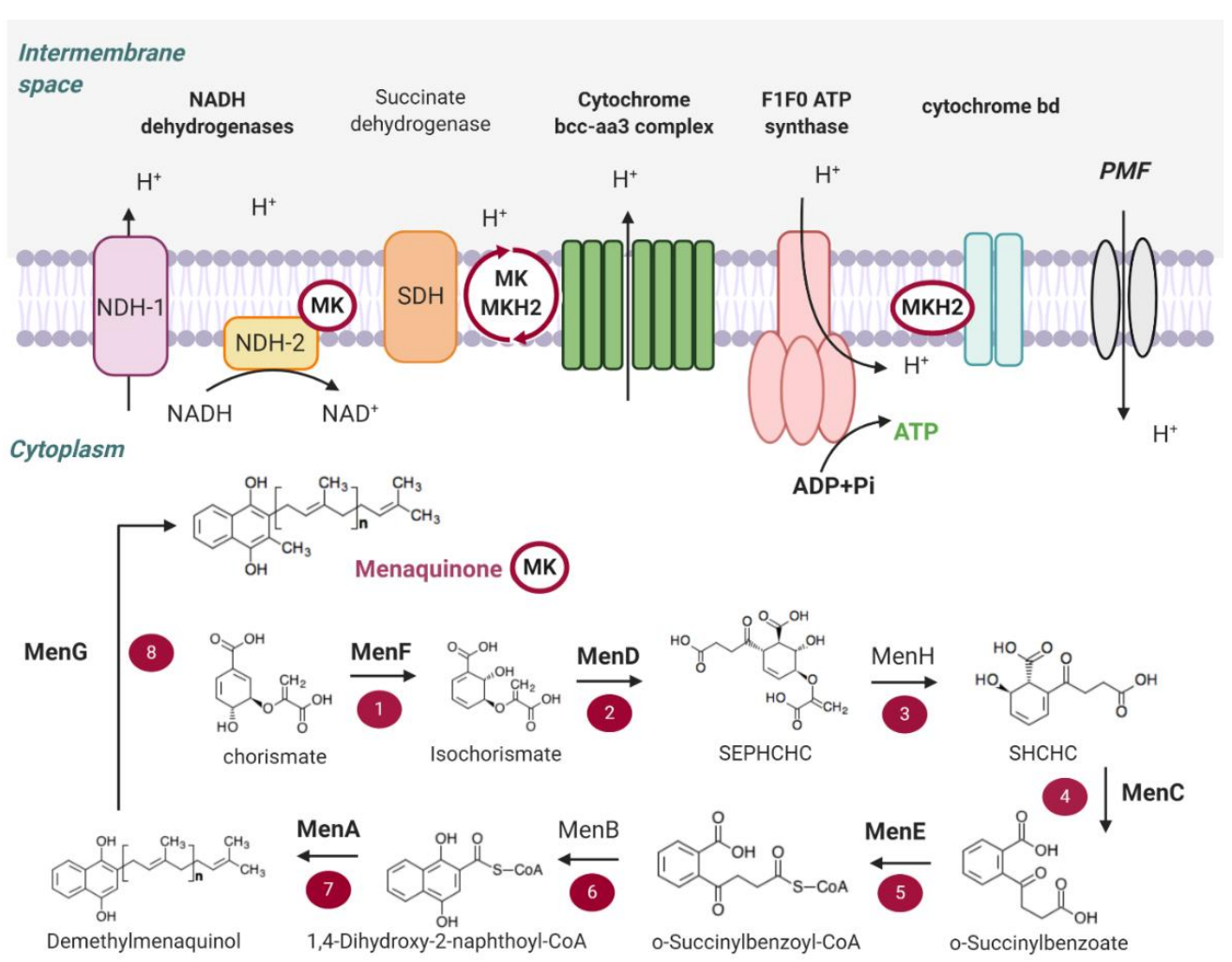

Figure 1. Schematic representation of the Mycobacterium tuberculosis (M. tb) electron transport chain (ETC) and menaquinone (MK) biosynthesis pathway. Electrons provided by NADH are fuelled to the ETC by the NADH dehydrogenases (mainly NDH-2 in $M$. $t b$ ), leading to the reduction of menaquinone (MKH2). MK is the sole carrier of electrons across the ETC and eight main enzymes are involved in its biosynthesis. The succinate dehydrogenases Sdh1 and Sdh2 also contribute to the reduction of the menaquinone pool. Electrons from the menaquinone pool are then transferred to one of the terminal oxidases, the proton-pumping Cyt-bcc-aa3 or the Cyt-bd oxidase, both of which catalyse the reduction of oxygen to water. Along the respiratory chain, protons are pumped across the membrane, which generate the proton motive force (PMF) that is then used by the $\mathrm{F}_{1} \mathrm{~F}_{0}$ ATP synthase to produce ATP.

\subsection{NADH Dehydrogenases}

$M . t b$ possesses three membrane-bound NADH dehydrogenases that are capable of transferring electrons to MK with the oxidation of NADH to NAD+. There is a proton-translocating type I NADH dehydrogenase (NDH-1) and two non-proton-translocating type II NADH dehydrogenases (NDH-2) [28]. NDH-2 has been chemically validated as a drug target in $M . t b$ [28-30]. Unlike NDH-1, it is absent in the mammalian genome, which is an advantage to develop specific inhibitors. NDH-1 is encoded by the nuo operon, NuoA-NuoN, (rv3145-rv3158) and the two NDH-2 are identified as $\mathrm{Ndh}$ (encoded by ndh $=$ rv1854c) and NdhA (encoded by ndhA = rv0392c) $[17,28]$. High-throughput transposon mutagenesis studies suggested that NDH-1 and NdhA are dispensable for growth, whereas $\mathrm{Ndh}$ is essential in vitro and in vivo [31-33]. However, recent studies have clarified the redundancy and essentiality of the NADH dehydrogenases. Detailed gene-deletion and gene-silencing studies of nuo, ndh, and ndhA performed by Vilcheze et al., established that individually, none of the NADH dehydrogenases are essential in vitro or in vivo [34]. Beites et al. further demonstrated that NDH-2 enzymes are jointly essential for growth in the presence of long-chain fatty acids, but are dispensable for growth on some carbon sources such as glycerol [35]. Moreover, a strain deficient for NDH-2 activity is only mildly attenuated in mice [35]. Both studies agree that while $M$. $t b$ requires at least one non-proton-pumping NDH-2 enzyme for growth, chemically targeting NDH-2 alone will likely be inefficacious, but is conceivable as part of a rational drug combination. 


\subsection{Succinate Dehydrogenase}

Succinate dehydrogenase (SDH), also known as complex II of the ETC, couples the oxidation of succinate to fumarate with the reduction of MK to menaquinol (MKH2) in M. $t b$ [36]. This complex directly connects the tricarboxylic acid cycle and the OxPhos pathway, thereby playing a critical role in bacterial carbon metabolism and respiration [37]. Despite its significance, there has been a general reluctance to develop inhibitors against this complex due to the presence of a mammalian counterpart and the presence of two isotypes [38]. M. tb possesses two canonical SDH enzymes, Sdh1 and Sdh2, and an additional reversible fumarate reductase that can catalyse the reaction in both directions [39]. Independent transposon-site hybridization screens in $M$. tb suggest that Sdh1 is essential for optimal growth under aerobic conditions [32], whereas Sdh2 seems to play a more significant role in the growth arrest and dormancy of $M$. $t b$ during its transition from aerobic to hypoxic conditions [40]. SDH enzymes also appear to function as an important regulator of respiration in M. $t b$. The deletion of sdh1 results in perturbation of respiration, leading to an increased rate of oxygen consumption which prevented recovery of $M$. $t b$ from the stationary phase [41]. While the functional redundancy of these enzymes remains to be fully clarified, it is established that the SDH enzymes in $M$. $t b$ are phylogenetically and biochemically distinct from each other, as well as from the mammalian complex $[14,42,43]$. On this basis, it would be theoretically possible to selectively inhibit the mycobacterial SDHs without off-target effects, although functional redundancy and structural differences between the mycobacterial SDHs would pose a challenge.

\subsection{Menaquinone (MK) Biosynthesis}

As the sole lipoquinone in mycobacteria, MK has a central and essential role in OxPhos [44,45]. Its biosynthetic pathway is a highly attractive drug target space as it is absent in humans, and has been demonstrated to be critical for maintaining mycobacterial survival under aerobic and anaerobic conditions [46]. In M. $t b$, the biosynthesis of MK mirrors that of Escherichia coli, in which the pathway has been better characterised [45]. Eight enzymes (MenF, MenD, MenH, MenC, MenE, MenB, MenA and MenG) are involved in the pathway, with MenF catalysing the first committed step of the conversion of chorismate [14]. Not all of the genes encoding for the MK synthesis pathway seem to be essential. Through initial transposon studies and confirmation by high-resolution phenotypic profiling experiments, most MK biosynthesis enzymes have been reported to be essential via transposon mutagenesis in H37Rv for $M . t b$ growth, except for MenF, whose deletion resulted in a growth defect in M. $t b$ [31-33].

Small molecules inhibiting MenD, MenE, MenB, MenA and MenG, and have been reported [47-51]. MenD is a thiamine diphosphate-dependent enzyme which catalyses the second step of MK biosynthesis. It uses 2-oxoglutarate and isochorismate for the synthesis of 2-Succinyl-5-enolpyruvyl-6hydroxy-3-cyclohexene-1-carboxylate (SEPHCHC). MenE encodes for an o-succinylbenzoate-CoA ligase that converts o-succinylbenzoate (OSB) to OSB-CoA, and is the fifth step of MK biosynthesis in $M$. $t b$. It is responsible for the addition of a CoA group via an OSB-AMP intermediate [50]. MenB encodes for a 1,4-dihydroxy-2-naphthoyl-CoA (DHNA-CoA) synthase that catalyses the formation of DHNA-CoA from o-succinylbenzoate-CoA and is the sixth step of the MK biosynthesis [52]. MenA encodes for a DHNA-octaprenyltransferase, which is involved in the seventh step of the MK biosynthesis. It catalyses the conversion of 1,4-dihydroxy-2-naphthoate (DHNA) to demethylmenaquinone (DMK), and uses a variety of allylic isoprenyl diphosphates as substrates, requiring at least three isoprene units [46,49]. Bacterial MenA was reported to be homologous to the eukaryotic UbiA [53]. Additionally known as UbiE, MenG (rv0558) catalyses the methylation of DMK-9 using S-adenosylmethionine to form MK [54]. This reaction is the last step of MK biosynthesis in $M$. $t b$. That these enzymes of the MK biosynthesis pathway can be pharmacologically inhibited demonstrate their essentiality and highlight their potential as drug targets. 


\subsection{Terminal Oxidases}

$\mathrm{MKH} 2$ is reoxidised with the transfer of electrons to branched routes of terminal respiratory oxidases or reductases. In $M$. $t b$, there are two terminal oxidases present which catalyse the four-electron reduction of oxygen to water, namely the proton-pumping Cyt-bcc-aa3 supercomplex and an alternative cytochrome bd oxidase (Cyt-bd) [39].

Cytochromes bcc and aa3 (also known as complexes III and IV) are encoded by qcrCAB and ctaB, $\mathrm{ctaC}, \mathrm{ctaD}, \mathrm{ctaE}$, respectively, and form a supercomplex of Cyt-bcc-aa3 in mycobacteria [55-57]. As this complex is proton-pumping, it is energetically more favourable for optimum growth and seems to act as the primary respiratory route in $M . t b$ under aerobic conditions [15]. Through inducible repression and genetic deletion, elegant studies revealed that, while the Cyt-bcc-aa3 complex is required for optimal $M$. tb growth rates in vitro and in mice, it is not strictly essential for growth nor persistence as long as the alternate Cyt-bd oxidase is expressed [35].

Following the first purification and initial characterisation of a hybrid respiratory complex consisting of M. tb cytochrome bcc and Mycobacterium smegmatis (M. smeg) cytochrome aa3 [56], the crystal structure of the Cyt-bcc-aa3 supercomplex of M. smeg has been recently solved by cryo-EM by two independent groups to a resolution of 3.3-3.5 $\AA$ [57,58]. This has enabled the full visualization of the supercomplex with its associated subunits, including cytochrome bcc subunits QcrC, QcrA (the Rieske iron-sulphur protein) and QcrB in a dimeric form with their respective prosthetic groups $[57,58]$. These studies shed light on the direct internal transfer of electrons from MKH2 to oxygen without the need for a separate cytochrome c electron shuttle as in other respiratory systems, and identifies novel subunits that contribute to the stability of the supercomplex, including an enzymatically active superoxide dismutase (SOD1). The presence of SOD1 in the bcc-aa3 supercomplex suggests the need for efficient ROS detoxification at a site dealing with a high amount of oxygen. Altogether, the structural information obtained from these studies is possibly relevant for further rationale-based TB drug discovery studies for inhibitors of this complex due to the high degree of sequence similarity of the quinol oxidation (Qp) site between $M$. tb and M. smeg, the site of inhibition of the TB drug candidate Q203 and other known QcrB inhibitors discovered thus far.

The bacterial-specific Cyt-bd is less characterised in $M . t b$ [59]. The pathogen harbours genes encoding the two main subunits, $C y d A$ and $C y d B$, and a putative $A B C$ transporter $C y d D C$, which has been proposed to be important for the assembly of the cytochrome in E. coli [60-63]. Genetic inactivation of the Cyt-bd-encoding genes in $M$. tb presented no loss of bacterial fitness and did not significantly impact ATP homeostasis under standard aerobic growth conditions, nor did it affect growth and persistence of $M . t b$ in mice $[35,64,65]$. To date, two structures of the Cyt-bd have been reported in Geobacillus thermodenitrificans and E. coli $[66,67]$, and these studies have highlighted the structural diversity within this family of enzymes. Given the low sequence homology of mycobacterial Cyt-bd to that of G. thermodenitrificans and E. coli [68], further structural studies of these enzymes in mycobacteria would be necessary to aid in drug development against the $M$. $t b$ Cyt-bd oxidase. While structural and biochemical information are currently lacking for the $M$. $t b$ Cyt-bd, similarities can be drawn with the E. coli homologue, which exhibits a very high affinity to oxygen and is non-proton-pumping, making it less efficient energetically compared to proton-pumping oxidases [69-71]. These characteristics would indicate a role of this terminal oxidase in bacterial survival in environments of low oxygen tension and protection against oxidative stress, even though it appears to function efficiently under normoxic conditions as well [65]. The upregulation of the cydAB operon has been reported for $M$. $t b$ under hypoxia and in the presence of NO, as well as during the chronic phase of infection in mice [72-74], and when the function of the Cyt-bcc-aa3 is compromised [32,59-61,75-77].

\subsection{ATP Synthase}

$M$. tb possesses a $\mathrm{F}_{1} \mathrm{~F}_{0}$ ATP synthase consisting of two functional domains, a membrane-embedded F0 unit and an external F1 domain, which is linked by central and periphery stalks on which F0 rotates [78]. This rotation is powered by a flow of protons down the electrochemical gradient of the PMF, 
and drives a cycle of conformational changes in the catalytic F1 domain, resulting in successive ADP binding and entrapment, ADP phosphorylation to form ATP and ATP release [79]. Conventionally, the ATP synthase is also capable of ATPase activity when intracellular ATP levels are high and the PMF is low, hydrolysing ATP while pumping protons across the cytoplasm to re-energise the PMF [80]. In mycobacteria however, the ATP synthase has been characteristically observed to have suppressed ATP hydrolysis activity, which has been postulated to be an adaptation to conserving ATP under low oxygen tensions $[39,78,81,82]$.

In $M . t b$, the $\mathrm{F}_{1} \mathrm{~F}_{0}$ ATP synthase is encoded by the atpBEFHAGDC operon and is essential for the viability of replicating and non-growing $M . t b[31-33,83]$, highlighting its critical role in ATP production and in maintaining a respiratory electron flow in all metabolic states [84]. Even though intracellular ATP levels in non-replicating $M . t b$ are significantly reduced compared to replicating bacilli, basal levels of ATP are still maintained in non-replicating states $[19,21]$. The essentiality of the ATP synthase in these conditions is underlined by the fact that its pharmacological inhibition by BDQ, a specific ATP synthase inhibitor, kills hypoxic, non-replicating $M . t b$ [83].

Interestingly, the mycobacterial ATP synthase is deprived of efficient ATP hydrolysis activity [82]. As a step towards uncovering the molecular basis of the extreme latency of ATP hydrolysis, a crystal structure of the M. smeg catalytic F1 domain revealed similarities with the Caldalkalibacillus thermarum F1-ATPase, which also hydrolyses ATP poorly [85]. This is likely due to an arrest in the catalytic rotary cycle of the F1 component, resulting in the inability to release products of ATP hydrolysis. The $\varepsilon$-subunit of the F1 module of $M$. $t b$, whose structure has been recently solved by nuclear magnetic resonance (NMR), has been implicated in the regulation of ATP hydrolysis. The removal of its C-terminal resulted in an increased ATP hydrolysis rate and decreased ATP synthesis [86]. Furthermore, Saw et al., demonstrated that this site is amenable to chemical inhibition in M. smeg by epigallocatechin gallate, the most abundant catechin in green tea [87]. Other subunits involved in the regulation of ATP hydrolysis include the $\gamma$ and $\alpha$ - subunits of the F1 module $[88,89]$. Altogether, these advances in the understanding of the $\mathrm{F}_{1} \mathrm{~F}_{0}$ ATP synthase aid in identifying new, specific inhibitors that either block de novo ATP synthesis and/or activate ATP hydrolysis, with the aim of depleting the residual pool of ATP in M. $t b$.

\subsection{Proton Motive Force (PMF)}

As in all other bacteria, an energised cell membrane is essential for the viability and growth of $M . t b$ in all metabolic states [19]. The generation and maintenance of a PMF, consisting of an electrical potential due to charge separation across the membrane and a chemical potential of protons, is, therefore, vital and occurs mainly through the proton-pumping components of the ETC [14]. A PMF of about $-110 \mathrm{mV}$ has been measured both in aerobic, replicating and in hypoxic, non-growing $M$. $t b$, indicating that even in a non-growing state, the bacteria maintain a similarly energized membrane [19]. This PMF is less than the typical PMF range of -180 to $-200 \mathrm{mV}$ observed in other bacteria, a difference which has been postulated to be an adaptation to host physiological environments of low nutrient levels and/or terminal electron acceptors $[39,78,90]$.

\section{Overview of the Inhibitors Targeting the OxPhos Pathway}

\subsection{NADH Dehydrogenases}

NADH dehydrogenases play a major role in maintaining mycobacterial respiratory chain energization by using MK as an electron carrier. NDH-1 is non-essential for mycobacterial growth and for persistence $[19,34]$. Therefore, no drug development is currently in progress for inhibitors of mycobacterial NDH-1 [39]. NDH-2 is widespread in bacteria and the mitochondria of fungi, plants and some protists. In some organisms, more than one copy is present [91]. Notably, NDH-2 (Ndh and $\mathrm{NdhA}$ ) are absent in mammalian genomes, suggesting a potential leading target for anti-mycobacterial drug development. 
Several inhibitors have been found to target NDH-2 in mycobacteria, including the phenothiazines, quinolinyl pyrimidines and 2-mercapto-quinazolinones (Table 1). It is also thought that NDH-2 plays a role in the reduction of the anti-leprosy drug clofazimine (CFZ), leading to the production of reactive oxygen species (ROS) and, consequently, its bactericidal activity against $M$. $t b$ [92]. However, CFZ is still potent against a $M$. $t b \Delta$ ndh-2 mutant strain, indicating that CFZ does not require activation by $\mathrm{NDH}-2$ to exert its anti-mycobacterial potency [35]. Further studies will be needed to understand the mechanism of action of CFZ against mycobacteria. The CFZ analogue TBI-166 is more potent than CFZ against $M$. $t b$ in vitro, and it is at least as potent as CFZ in acute and chronic murine models of TB while being potentially associated with less skin discoloration [93]. A study by Beites et al. demonstrated that the inactivation of both NDH-2 ( $\Delta$ ndh-2) can be achieved in the absence of fatty acids in the growth media. Interestingly, rotenone, an inhibitor of NDH-1, has bactericidal activity against $\Delta \mathrm{ndh}-2$, which suggests that NDH-1 and NDH-2 have a redundant role in $M . t b$ [35].

The phenothiazines, a class of antipsychotic drugs, including thioridazine, chlorpromazine and trifluoperazine, have been widely studied against $M$. $t b$. They have activity in vitro against $M . t b$ with minimum inhibitory concentration (MIC) of thioridazine, chlorpromazine and trifluoperazine ranging between 5 to $32 \mu \mathrm{g} / \mathrm{mL}$ [94-98]. However, their limited potency coupled with an unfavourable toxicological profile preclude clinical use for TB treatment [99]. However, phenothiazines accumulate in macrophages and are particularly potent against intracellular $M . t b[100,101]$. Current efforts aim at developing new phenothiazine derivatives with improved activity against $M$. $t b$ and reduced toxicity [102-105].

Another class of NDH-2 inhibitors is the quinolinyl pyrimidines [106]. This class of compounds was identified during an NDH-2 target-based high-throughput screening of more than 100000 compounds. The series showed a good inhibitory range against $M$. $t b$ in vitro, with $\mathrm{MIC}_{50}$ below $1 \mu \mathrm{g} / \mathrm{mL}$ [106]. In contrast to the phenothiazines, the quinolinyl pyrimidines series is not hemolytic.

CBR-1825 and CBR-4032 are two representatives compounds of the thioquinazoline (TQZ) and tetrahydroindazole scaffolds, respectively, that were identified in a high-throughput screen of over 800000 compounds in mycobacterial inverted membrane vesicles (IMVs) [29]. The assay was designed to identify small-molecules interfering with ATP production. CBR-1825 and CBR-4032 had an MIC 50 of $0.43 \mu \mathrm{M}$ and $6.6 \mu \mathrm{M}$, respectively, when tested, and no apparent cytotoxicity [29]. Both compounds are bactericidal against $M . t b$ in vitro and seem to perturb NADH turnover. Sequencing of three escape mutants resistant to TQZ revealed a non-synonymous mutation in the promoter region of ndhA (rv0392c), suggesting that these compounds target NDH-2.

A 2-mercapto-quinazolinones cluster of hits $(1,2$, and 3$)$ was identified in a screening of a commercial diversity library [30]. Compound 1 potently inhibiting $M$. $t b$ growth in vitro in the low micromolar range without cytotoxicity against HepG2 cells [30]. Bioenergetic analyses conducted in cells in which the membrane potential was uncoupled from ATP production revealed a decrease in oxygen consumption rates (OCR) in response to the inhibitor, while IMVs showed mercapto-quinazolinonedependent inhibition of ATP production when NADH was the primary electron donor of the respiratory chain. Enzyme kinetic studies further demonstrated non-competitive inhibition of recombinant $M$. $t b$ Ndh protein [30]. Resistance to the compounds in $M$. $t b$ was conferred by promoter mutations in ndhA. Interestingly, hypersusceptibility to this class of compounds was observed when ndhA was deleted, suggesting that NDH-1 and other electron donors cannot compensate for the inhibition of NDH-2 by 2-mercapto-quinazolinones [30]. Chemical optimisation is required to improve the pharmacokinetics (PK) properties of this interesting series [30].

Quinolinequinones (QQ) exert mycobactericidal activity through NDH-2 inhibition. Interestingly, QQ prevent the emergence of persistent cells in a time- and dose-dependant manner in Mycobacterium bovis BCG in vitro [107]. This scaffold is known for its anti-cancer and anti-inflammatory properties, and can be modified to give rise to derivatives with anti-mycobacterial activity [108-110]. Mulchin $\mathrm{BJ}$ et al. synthesised a range of 6,7-substituted-5,8-quinolinequinones, and their anti-mycobacterial activities were assessed against $M$. bovis BCG, in addition to their anti-tumour and anti-inflammatory 
properties [111]. Several compounds containing amine and halogen functionality exhibited tuberculostatic activity in the range $3-12.5 \mu \mathrm{g} / \mathrm{mL}$ [111]. The derivative QQ8c stimulated NADH oxidation in $M$. $t b$ and M. smeg IMVs. Ndh overexpression enhanced the stimulation of NADH oxidation [107]. This increase in NDH-2 catalytic activity has been associated with the production of lethal concentrations of ROS. Recently, Santoso et al. synthesised a library of 32 new QQ derivatives, with one derivative (16b) showing enhanced in vitro activity against $M$. $t b$ [112]. Activation of NADH-dependent oxygen consumption in M. smeg IMVs in the presence of $16 \mathrm{~b}$ suggests that this new inhibitor has the same anti-mycobacterial mechanism of action than QQ8c [112].

Table 1. Structures of the NADH dehydrogenase inhibitors discussed in this review.

\begin{tabular}{|c|c|c|c|}
\hline Chemical Class & Represented by & Structure & References \\
\hline \multirow{3}{*}{ Riminophenazines } & Clofazimine & & [113] \\
\hline & & & \\
\hline & TBI-166 & & [114] \\
\hline \multirow{3}{*}{ Phenothiazines } & Chlorpromazine & & \\
\hline & Thioridazine & & \\
\hline & Trifluoperazine & & \\
\hline
\end{tabular}


Table 1. Cont.

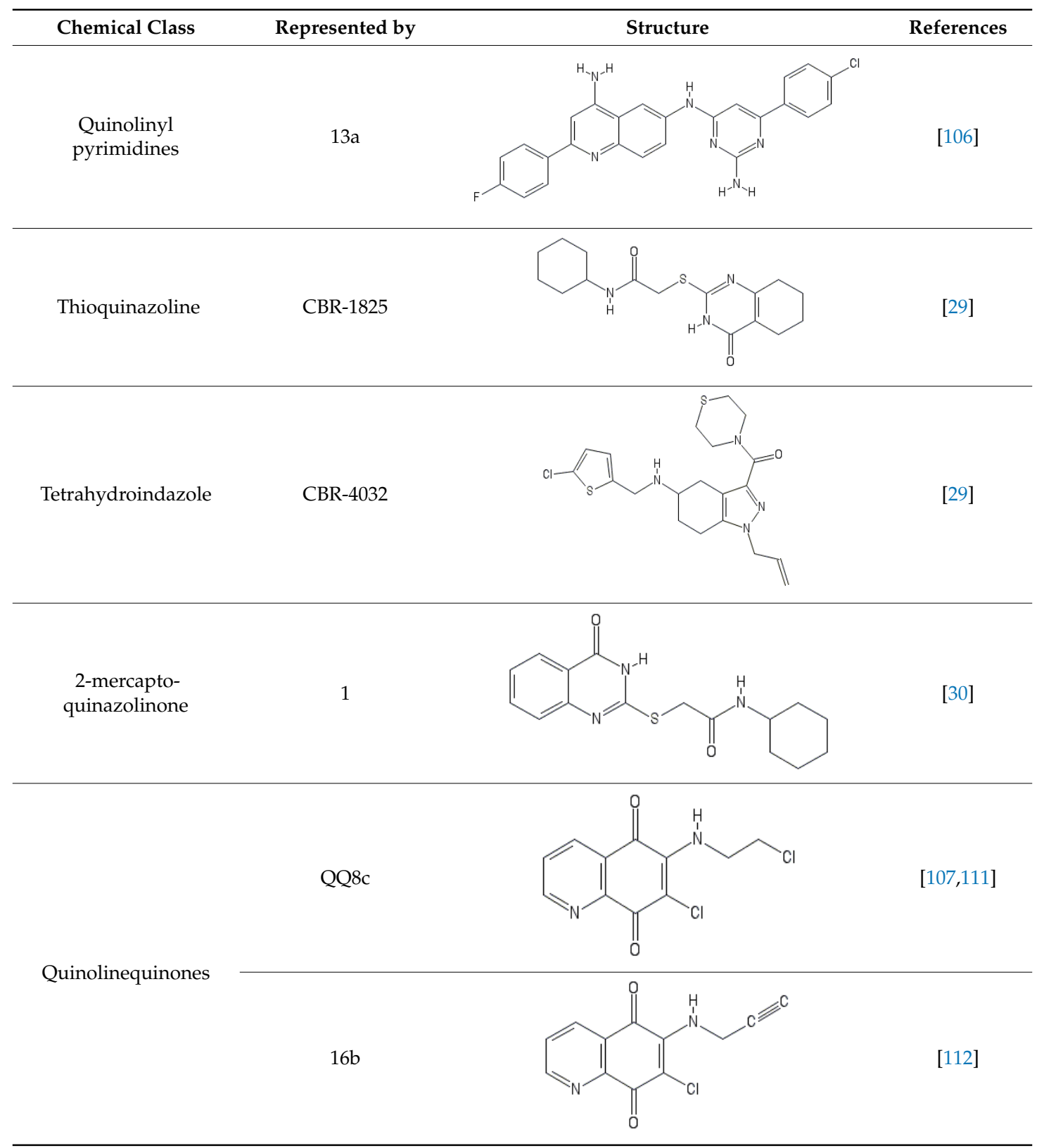

\subsection{Menaquinone (MK) Biosynthesis}

The essentiality of this pathway makes it an attractive target for anti-TB drug development. To date, chemical inhibitors of MenA, MenB, MenG, MenD and MenE have proven efficacious in inhibiting $M$. $t b$ growth. Inhibitors of the MK biosynthesis discussed in this review are listed in Table 2. 
Table 2. Menaquinone (MK) biosynthesis inhibitors discussed in this review.

\begin{tabular}{ccc}
\hline Chemical Class & Represented by & Ref \\
\hline MenD inhibitors & & \\
\hline methyl succinylphosphonate & 2 & [115]
\end{tabular}

\begin{tabular}{c}
\hline MenE inhibitors \\
$\begin{array}{c}\text { vinyl sulphonamide } \\
\text { MeOSB-AVSN }\end{array}$
\end{tabular}

$\begin{gathered}\text { benzophenone O-methyl oxime } \\ \text { derivatives }\end{gathered}$
$\begin{gathered}\text { 4-bromophenyl)[2-fluoro-4- } \\ \text { [6-(methyl-2-propenylamino) }\end{gathered}$

\subsubsection{MenD}

Studies by Fang et al. identified two compounds, methyl succinylphosphonate (2) and succinylphosphonate (1), that inhibit $M . t b \mathrm{MenD}$ at a Ki of 0.7 and $16 \mu \mathrm{M}$, respectively [115]. These inhibitors are structural analogues of the substrate 2-oxoglutarate and bind covalently to MenD. The resolution of the three-dimensional structure of $M$. $t b$ MenD by NMR will support target-based drug design [119]. 


\subsubsection{MenE}

Due to the instability of OSB, efforts to create MenE inhibitors were mainly focused on the inhibition of the assembly of the OSB-AMP intermediate. Lu et al. identified three potential MenE inhibitors using the OSB as a scaffold [50,120]. In these inhibitors, the AMP moiety was replaced with a bioisosteres sulphamate, a sulphamide, and a vinyl sulphonamide group [120]. The vinyl sulphonamide compound was the most potent with $\mathrm{IC}_{50}$ of $5.7 \mu \mathrm{M}$ against the purified $M . t b \mathrm{MenE}$ enzyme [50].

\subsubsection{MenA}

Several inhibitors have been identified to target MenA. Aurachin RE is a natural product from Rhodococcus erythropolis JCM6824, and harbours potent activity against a wide range of Gram-positive and Gram-negative bacteria, including Corynebacterium glutamicum [121]. Using the aurachin RE scaffold, Debnath et al. synthesised a series of more than 400 derivatives that were assessed for their ability to specifically inhibit the $M$. $t b$ MenA enzyme [49]. Compounds with IC $_{50}$ lower than $20 \mu \mathrm{M}$ against $M$. $t b$ and M. smeg, and without activity against Staphylococcus aureus MenA enzyme, were identified [49]. The lead compound of this series, (R)-13, had a MIC of $2.3 \mu \mathrm{g} / \mathrm{mL}$ against $M$. $t b$. The compound is also bactericidal against hypoxic, non-replicating mycobacteria, suggesting a high MK turnover rate during persistence.

Ro 48-8071, a (4-bromophenyl)[2-fluoro-4-[[6-(methyl-2-propenylamino)hexyl]oxy] phenyl]methanone developed by Hoffman La Roche Inc is a known inhibitor of oxidosqualene cyclase, which is involved in cholesterol biosynthesis in mammalians. It is effective against $M$. $t b, M$. bovis BCG and M. smeg [46,53]. The target of Ro 48-8071 was inferred from metabolic labelling experiment in M. bovis $B C G$ [46]. The synthesis of a neutral, apolar liquid, which was biochemically identified as MK through the incorporation of radiolabelled isoprenoid precursors and methionine, was inhibited in the presence of Ro 48-8071 [46]. Moreover, when M. smeg was treated with Ro 48-8071, a reduction of 2.5-3.3-fold in the concentrations of DMK-9 and MK-9 was observed, suggesting that the compound inhibits the late steps of MK biosynthesis in mycobacteria. Ro 48-8071 decreased the oxygen consumption in $M$. smeg and $M$. $t b$, a phenotype that was rescued by MK supplementation. To validate MenA as the direct target of Ro 48-8071, MenA activity was assessed in membranes prepared from a recombinant E.coli strain expressing the M. $t b$ MenA [46]. An eight-fold decrease in MenA activity was observed upon treatment with Ro 48-8071, indicating that MenA is the target of this inhibitor. Structure-activity relationship (SAR) studies led to the derivative CSU-20 which has improved MIC against $M . t b$ and was bactericidal against hypoxic, non-replicating mycobacteria [46]. Dhiman et al. showed that Ro 48-8071 has dual activity against MenA by behaving as a non-competitive inhibitor of the substrate DHNA, but also as a competitive inhibitor of isoprenyl diphosphate [122].

The bicyclic long-chain fatty acids 7-methoxy-2-naphthol-based inhibitors also target MenA $[117,123,124]$. Berube et al. tested four compounds of this series (NM-1 to NM-4) for their ability to inhibit MenA and $M$. tb growth. The most active compound, NM-4, had an $\mathrm{MIC}_{90}$ of $4.5 \mu \mathrm{M}$ and was bactericidal against replicating and non-replicating $M$. $t b$ [117]. NM-4 was synergistic with BDQ, CFZ and imidazopyridine ND-10885 in vitro against $M$. $t b$, with culture sterilisation observed after 21 days of incubation. This new lead is non-cytotoxic, specific for Gram-positive bacteria, and amenable to chemical optimisation, properties that could be exploited to optimise the chemical series [124]. Further characterisation work on the $\mathrm{PK} / \mathrm{PD}$ properties and in vivo activity remains to be undertaken.

\subsubsection{MenG}

Benkovic et al. identified inhibitors of CcrM, an essential DNA methyltransferase in the $\alpha$-proteobacteria Caulobacter crescentus, which were later demonstrated to inhibit MenH in B. subtilisan orthologue of $M$. $t b$ MenG [118]. The derivative compound 12a, a diphenylborinic acid quinoline ester, was the most active MenH inhibitor in Bacillus subtillis. In M. $t b$, the MICs of the derivatives 
range from 0.31 to $0.64 \mu \mathrm{g} / \mathrm{mL}$, and to our knowledge, no further SAR and target validation studies have been performed.

Another chemical class of MenG inhibitors, the biphenyl amides, were also identified in a whole-cell screen targeting the mycobacterial respiratory pathway. 168 small molecules with anti-TB activity from GlaxoSmithKline were screened against a $M$. bovis BCG strain containing a mWasabi reporter fused to the putative promoter of cydAB, a reporter system used to identify drugs targeting respiration [51,125]. The compound GSK1733953A, also known as DG70, induced the expression of the reporter strain compared to untreated control. This bactericidal compound showed specific activity against drug-susceptible and drug-resistant $M$. $t b$. DG70 was bactericidal against nutrient-starved $M$. $t b$, which mimics a sub-population that is particularly difficult to kill [51]. MK-4 supplementation rescued the bactericidal potency of DG70, implying that the MK biosynthesis pathway is involved in the mechanism of action of this compound. Resistant mutants selected in $M$. $t b$ H37Rv with DG70 harboured mutations V20A, F118L, W75A, and S188A in MenG, leading to high-level resistance to DG70. DG70 was also shown to block de novo biosynthesis of MK, highlighting its role as an inhibitor of MenG. Interestingly, this compound showed synergism with BDQ, isoniazid (INH) and rifampicin (RIF) in time-kill assays, suggesting that MenG inhibitors could be part of a potent drug combination [51].

\subsection{Inhibitors of the Cyt-bcc-aa3 Complex}

A number of chemically-diverse and distinct scaffolds target the $M$. $t b$ cytochrome bcc oxidase by binding at the Qp site of the QcrB subunit, otherwise known as the stigmatellin pocket. The Qp site is one of two quinol catalytic sites on QcrB. The promiscuous nature of this target has been attributed to its localization in the bacterial membrane, as with other membrane-associated targets $[54,68]$. In this section, we provide an overview of chemical classes reported to inhibit the Cyt-bcc-aa3 terminal oxidase (Table 3).

Table 3. Inhibitors of the Cyt-bcc-aa3 complex and the bd oxidase discussed in this review.

\begin{tabular}{|c|c|c|c|}
\hline Chemical Class & Represented by & Structure & Ref \\
\hline \multicolumn{4}{|c|}{ Cytochrome bcc inhibitors } \\
\hline Imidazopyridines & Q203 (Telacebec) & & [12] \\
\hline $\begin{array}{l}\text { Imidazo[2,1-b]thiazole- } 5 \\
\text {-carboxamide }\end{array}$ & ND-11543 & & [126] \\
\hline Imidazopyridine ethers & $19 \mathrm{e}$ & & [127] \\
\hline $\begin{array}{l}\text { Pyrazolo[1,5-a]pyridine-3- } \\
\text { carboxamide }\end{array}$ & TB47 & & [128] \\
\hline
\end{tabular}


Table 3. Cont.

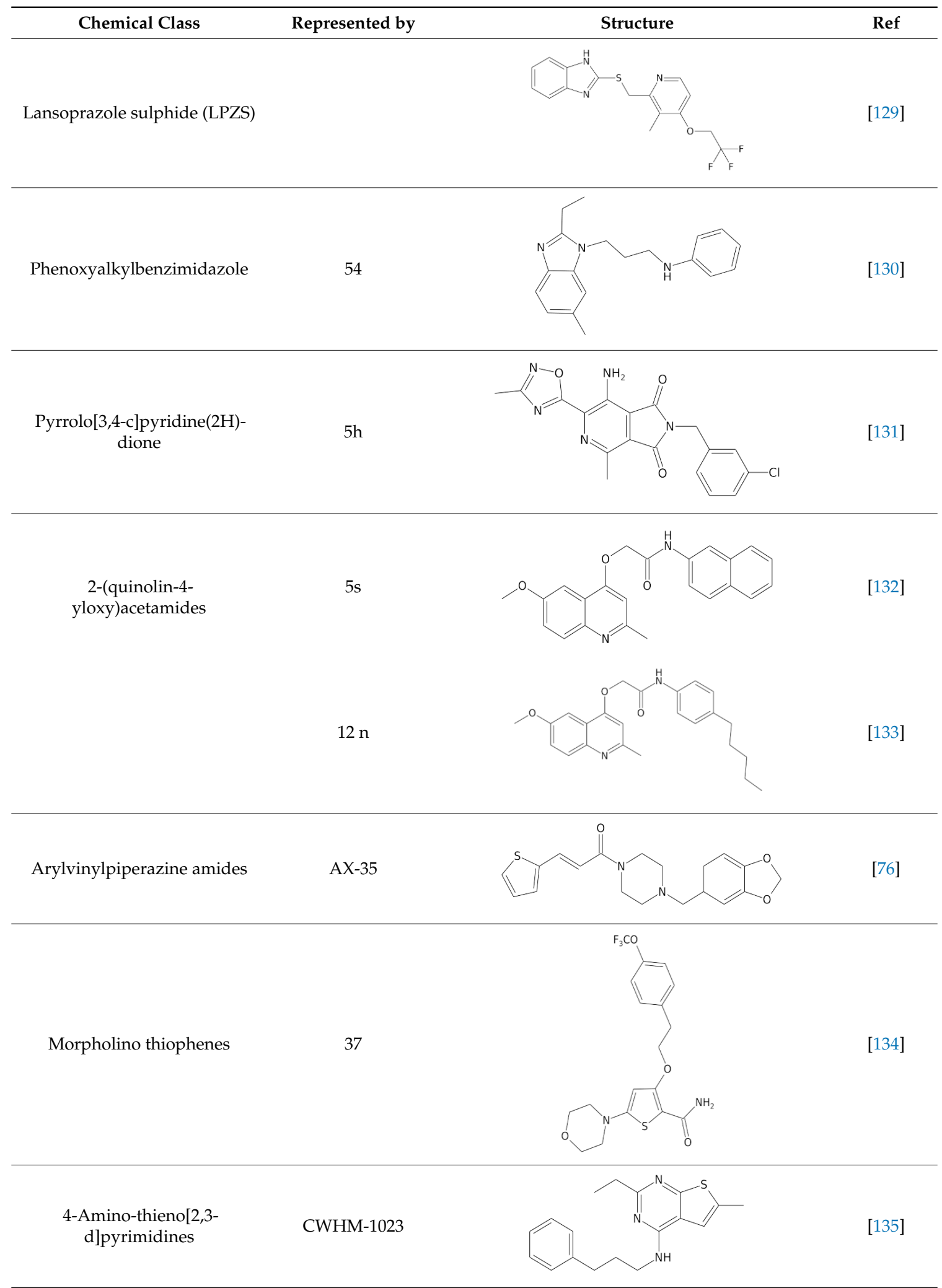


Table 3. Cont.

\begin{tabular}{cccc}
\hline Chemical Class & Represented by & Ref \\
2-Ethylthio-4- \\
methylaminoquinazolines
\end{tabular}

Several promising hits belonging to the chemical class of imidazopyridines (IPs) have been identified in independent screening programs [12,75,137-139]. Extensive efforts have been undertaken to optimise and to explore the SAR of this scaffold [126,140-143]. To date, the most advanced QcrB inhibitor is Q203, an IP derivative in Phase 2 clinical trials. The drug candidate was initially discovered in a phenotypic high-content screen in $M$. $t b$-infected macrophages and further optimised to achieve an $\mathrm{MIC}_{50}$ of $2.7 \mathrm{nM}$ against $M . t b \mathrm{H} 37 \mathrm{Rv}$ in vitro. Its activity is comparable to that of BDQ and INH in a mouse model of chronic TB infection [12]. In addition to its potency, the positive results from the Phase 1 and Phase 2a early bactericidal activity clinical trial indicate its safety and tolerability in TB patients, emphasizing the specificity of bacterial inhibition without affecting the human counterpart [144]. Resistant mutants generated to Q203 revealed amino acid mutations T313A or T313I in QcrB [12]. This interaction between Q203 and QcrB has recently been biochemically demonstrated by in-cell NMR using whole $M$. smeg cells expressing the $M$. $t b$ QcrCAB complex and a Q203 derivative, indicating target engagement at the Qp site of QcrB [145]. While bacteriostatic on its own in $M$. $t b, \mathrm{Q} 203$ becomes highly bactericidal when the alternate Cyt-bd oxidase is absent, as demonstrated in $M$. $t b$-infected macrophages and in a mouse model of acute TB infection [65,146]. Q203 is also highly bactericidal and potent against Mycobacterium ulcerans, reducing bacterial load in a mouse footpad infection model of Buruli ulcer by $99.99 \%$ at a dose of $0.5 \mathrm{mg} / \mathrm{kg}$ administered three times per week for four weeks [147]. This highlights additional opportunities for repurposing QcrB inhibitors against other organisms that do not harbour functional alternative terminal oxidases, such as M. ulcerans and Mycobacterium leprae.

Extended SAR studies of IPs imidazopyridine carboxamides led to the novel scaffold imidazothiazole carboxamides (ITA), of which analogues have nanomolar potency (MIC $<10 \mathrm{nM}$ ) against replicating and drug-resistant $M$. $t b$ [143]. Derivatives of this class also demonstrate intracellular activity in macrophages and in vivo [143]. Additionally, cross-resistance studies with strains harbouring QcrB mutations and dose-response studies in a M. tb strain without Cyt-bd oxidase indicate that these compounds target QcrB [143]. This series is promising for its tolerability and good oral bioavailability in mice [126].

Imidazopyridine ethers (IPEs) were identified from a biochemical screen of AstraZeneca's corporate compound collection aimed at identifying inhibitors of ATP homeostasis [127]. The extent of ATP synthesis inhibition, as measured in IMV of $M$. smeg, correlated well with anti-tubercular potency in $M$. $t b$, with a MIC of $0.03 \mu \mathrm{M}$ for some optimised derivatives [127]. While generating resistant mutants to the series was unsuccessful, target site deconvolution through a series of biochemical tests and cell-based assays indicated that these chemical entities target the Cyt-bcc-aa3 complex. These series have been deprioritised by the group due to their poor solubility and poor PK profile [127].

Structurally similar to the IPs, the pyrazolopyridine carboxamide series were designed as novel anti-tubercular agents through a scaffold hopping strategy $[148,149]$. The lead compound, TB-47, is currently in early-stage development. It has activity against replicating $M$. $t b$ in vitro with MICs of 0.016 to $0.5 \mu \mathrm{g} / \mathrm{mL}$ when tested against a panel of $M$. $t b$ drug-susceptible and drug-resistant 
clinical isolates, and a high-selective index. Furthermore, TB-47 is well-tolerated and has good oral bioavailability in rats. While it did not display bactericidal activity alone in mouse models of acute and chronic TB infection, TB-47 potentiated the activity of pyrazinamide (PZA) and RIF during an acute TB infection in mice [128]. The authors speculated that alteration of the $\mathrm{NADH} / \mathrm{NAD}^{+}$ratio triggered by QcrB inhibition sensitized the bacteria to the front-line drugs. While this hypothesis is interesting, it remains to be further explored since no positive interactions between RIF and the QcrB inhibitor Q203 in vitro have been observed [150]. Resistant mutants to TB-47 were generated in a M. smeg strain with a deletion of Cyt-bd oxidase, and whole-genome sequencing of the isolates revealed mutation H190Y in QcrB of M. smeg [128]. This residue, equivalent to H195 in M. tb, is located in the cd2 loop of QcrB, which is thought to interact with the Qp site [128].

A host cell-based screen of FDA-approved drugs of the Prestwick chemical library for compounds that protect lung fibroblasts from $M$. $t b$-induced cytotoxicity identified the gastric proton-pump inhibitor, lansoprazole (LPZ, Prevacid), as a potent hit compound [129]. LPZ is a prodrug that requires the host cell environment for conversion into lansoprazole sulphide (LPZS). Oral administration of LPZS significantly reduced bacterial burden during an acute TB infection in mice, and the compound lacks cytotoxicity, being well-tolerated in mice at a dose of $300 \mathrm{mg} / \mathrm{kg}$. Whole-genome sequencing of resistant mutants generated to LPZS revealed mutation L176P in QcrB, and cross-resistance studies with imidazopyridine amide compounds and the T313A mutant strain indicated a distinct binding mode [129]. A follow-up study demonstrated that when LPZ is administered orally or intraperitoneally (i.p.) to rats, conversion to the active metabolite LPZS is undetectable in plasma and lung tissue, whereas LPZS was highly stable after i.p. administration [151]. In spite of this, LPZ intake has been found to significantly protect against TB incidence in individuals based on a cohort study conducted using the United Kingdom Clinical Practice Research Datalink [152].

The phenoxyalkylbenzimidazole (PAB) series, with an excellent growth-inhibitory potency and low cytotoxicity, is another promising QcrB inhibitor $[130,153]$. The lead compound, 54 , demonstrated good efficacy against intracellular $M$. $t b$. Resistant mutants to PAB isolated in $M$. $t b$ revealed mutations in qcrB and rv1339, a gene of unknown function. Through additional cross-resistance studies, QcrB was implicated as the main target [130]. The mutations identified in QcrB were A179P, M342T, W312C, and W312G, residues of the Qp binding site. Interestingly, while PAB compounds are bacteriostatic against actively growing $M$. $t b$, as with other QcrB inhibitors such as Q203 and LPZS, they are bactericidal against $M$. $t b$ grown under conditions of nutrient starvation, in contrast to the lack of activity of other QcrB inhibitors in non-replicating models [129]. This discrepancy may be due to a potential involvement of a secondary target of $\mathrm{PAB}$, for instance, rv1339, the second gene in which mutations were identified from resistant mutants.

The screening of a library of small polar molecules in a distinctive chemical space conducted at the Novartis Institute for Tropical Diseases led to the identification of hit compound pyrrolo[3,4-c]pyridine-1,3(2H)-dione, which was further optimised to increase its stability by replacing the ester moiety with a methyl oxadiazole bioisostere [131]. Lead compound $5 \mathrm{~h}$ has an $\mathrm{MIC}_{90}$ below $0.156 \mu \mathrm{M}$ in replicating $M . t b$, and is non-cytotoxic. The high clearance and poor plasma exposure of $5 \mathrm{~h}$ in mouse PK studies could be improved by co-dosing with a pan-CYP inhibitor, such that a compound concentration above that of the MIC could be achieved in the blood for $6 \mathrm{~h}$ at a dose of $20 \mathrm{mg} / \mathrm{kg}$. While attempts at isolating resistant mutants to this novel chemical class were unsuccessful, $M$. $t b$ with a Cyt-bd oxidase deletion was hypersusceptible to the analogues. Moreover, the presence of mutation A317T in QcrB in this strain rendered M. tb resistant to the compounds, thus implicating QcrB in the mechanism of action of this class. Further studies on the pyrrolo[3,4-c]pyridine-1,3(2H)-diones will be aimed at improving their plasma concentration in vivo.

In 2013, GlaxoSmithKline published the results of a large phenotypic screening campaign against $M$. bovis BCG and $M$. $t b$, in which 177 hits belonging to several structurally distinct groups were identified [125]. To date, these chemical starting points have led to the discovery of two new classes of QcrB inhibitors, the 2-quinolin-4-yloxyacetamides (QOA) and the arylvinylpiperazine amides. Several 
SAR studies of the QOAs have been reported and are in agreement regarding the potency of this chemical entity against $M$. $t b$, the lack of toxicity in a zebrafish model and the narrow-spectrum activity specific for $M . t b[132,154,155]$. Independent work through cross-resistance studies and isolation of resistance mutants harbouring the mutation T313A in QcrB confirmed cytochrome bcc as the target of QOAs $[155,156]$. The solubility and stability of this series, as well as their in vivo potency, remain to be addressed $[133,154]$. The arylvinylpiperazine amides were generated through lead optimisation and SAR studies conducted with GW861072X from the GSK screen, which was an attractive starting point for its structural simplicity and potent activity against $M$. bovis and $M$. $t b$ [76]. The most potent analogues have improved MICs compared to the parent scaffold, displaying low cytotoxicity and activity against intracellular $M$. $t b$. The lead compound, AX-35 and two other analogues, AX-37 and AX-39, were also active in an acute TB infection model in mice. While isolation of $M$. $t b$-resistant mutants on agar proved unsuccessful, continual and increasing exposure of $M$. tb to AX-35 over several passages in liquid culture resulted in the selection of resistant clones harbouring the mutations S182P, M342V and M342I in QcrB. Cross-resistance studies provided insight on residues which were important for the binding of the compound to QcrB, indicating a slightly different interaction with the quinol binding pocket than Q203 and LPZS. Improving the metabolic stability of this series would likely improve the in vivo activity in mice, although these compounds appear to be more stable in human microsomes.

The morpholino-thiophenes were identified from the Lilly corporate library that was screened in an aerobic whole-cell phenotypic setting against $M$. $t b$. The series was extensively profiled and optimised, with the lead of this series having an $\mathrm{MIC}_{90}$ of $0.24 \mu \mathrm{M}$ against $M$. $t b$, a high-selective index and improved microsomal stability [134]. In an acute model of TB infection, the lead compound reduced the bacterial burden by $0.8 \log$ CFUs in mouse lungs. Cross-resistance studies of the compounds to $M$. tb strains harbouring QcrB T313I and M342T mutations indicated that the compounds interact with the quinol binding site of QcrB.

4-amino-thieno[2,3-d] pyrimidines were found to inhibit the growth of M. smeg in a screen of small-molecule nucleotide mimetics from ChemBridge Corporation. The most potent compound of the series, CWHM-1023, had an $\mathrm{IC}_{50}$ of $0.083 \mu \mathrm{M}$ against $M$. $t b$ [135]. Resistant mutants raised to CWHM-1023 in M. tb had mutations A178T, A178V, V338G, G175S or G315S in QcrB, and this target was further confirmed by the increased susceptibility of a $M$. $t b$ strain lacking Cyt-bd oxidase to the compounds.

The most recent class of Cyt-bcc-aa3 inhibitors identified are the quinazoline derivatives, 2-ethylthio-4-methylaminoquinazolines [77]. The most potent derivatives have activity against in vitro and intracellular $M . t b$ in the micromolar range, and have low cytotoxicity in human hepatocytes. The lead compound 11726148 has a low clearance in human microsomes and was active in an acute TB infection model. Whole-genome sequencing of $M$. $t b$ resistant mutants to the quinazoline derivatives revealed mutations Trp312Gly and Gly175Ser in QcrB. Interestingly, one escape mutant has a SNP in qcrA leading to the substitution of Leu356Val in QcrA, the Rieske iron-sulphur protein of the Cyt-bcc-aa3. Mapping of the mutated residues on a model of the M. smeg Cyt-bcc-aa3 complex [58] indicated that all of the mutated residues, including Leu356Val in QcrA, map to the Qp site of QcrB. This is in line with the Q-cycle model, in which quinol oxidation occurs at the interface of cytochrome $\mathrm{b}$ and the $2 \mathrm{Fe}-2 \mathrm{~S}$ cluster domain of the Rieske protein, which make up the catalytic Qp site [57,157]. Cross-resistance studies confirmed the target of QcrB, and also reveal the role of Leu356Val in QcrA in its interaction with other QcrB inhibitors, namely Q203, AX-35, and LPZS. With the implication of QcrA in the pharmacological inhibition of Cyt-bcc-aa3, novel inhibitors can be generated which target both QcrB and QcrA subunits using structure-assisted drug-design to decrease the likelihood of resistance to QcrB inhibitors. Within this novel class, lead compound 11726148 appears the most amenable for further optimisation, as its phenyl moiety can be changed on different heterocycles to improve pharmacological properties. 
The Qp site of the Cyt-bcc-aa3 complex is particularly susceptible to chemical inhibition, as evident from the multitude of structurally diverse and distinct compounds detailed above. It has been consistently observed across several of the studies that characteristic consequences of cytochrome bcc inhibition include a general depletion of intracellular bacterial ATP levels, an upregulation of Cyt-bd oxidase, and an increase in OCR and bacterial respiration due to Cyt-bd $[12,76,77,128-130,134,135,155$, 158]. This compensation by the alternate terminal oxidase leads to an incomplete respiratory shutdown in $M . t b$, resulting in the bacteriostatic nature of cytochrome bcc inhibitors alone. However, with the deletion of Cyt-bd, mycobacterial respiration is effectively blocked, and cytochrome bcc inhibitors become bactericidal $[65,76,77]$. Taken altogether, these concerted efforts have generated a potential pool of backup cytochrome bcc inhibitors as Q203 continues in clinical trials. Additionally, these findings have highlighted the extreme vulnerability of $M$. $t b$ without both of its terminal oxidases, and the immense potential of both respiratory branches as drug targets.

\subsection{Inhibitors of Cyt-bd Oxidase}

Aurachin D is a quinone analogue of the aurachin class that inhibits Cyt-bd oxidase of E. coli [136] (Table 3). When tested against membrane vesicles of $M$. smeg, aurachin D demonstrated dose-dependent inhibition of oxygen consumption of up to 50\% [159]. Oxygen consumption was further inhibited by $90 \%$ in membrane vesicles without QcrCAB, indicating the likelihood of aurachin D targeting Cyt-bd in mycobacteria as well. On its own, aurachin D did not display activity against replicating M. smeg nor $M . t b[159,160]$. In spite of the lack of observable activity alone, aurachin $\mathrm{D}$ in combination with Q203 resulted in a $~ 10$-fold decrease of the MIC of Q203 against $M$. $t b$, as well as enhanced bactericidal killing of $M$. $t b$ by $>2 \log 10$ CFUs, demonstrating that aurachin D does indeed potentiate the activity of Q203 [160]. However, it remains to be demonstrated that aurachin D is a specific Cyt-bd inhibitor in mycobacteria as given its structural relation with MK, it may interfere with other respiratory complexes. This is particularly important since it was recently demonstrated that small-molecules are able to enhance the bactericidal potency of QcrB inhibitors without targeting the Cyt-bd [161].

It was shown that genetically inactivating both terminal oxidases completely abolished the in vitro growth of $M . t b$ [35]. This also dramatically impacted bacterial fitness in vivo in mice, with a strain having a knockdown of Cyt-bcc-aa3 and a knockout of Cyt-bd being unable to establish an initial infection [35]. Even if an initial infection could be first achieved by regulating the expression of one of the terminal oxidases, the absence of both terminal oxidases led to severe persistence defects, with a decrease of five orders of magnitude in bacterial load in 35 days [35]. These findings are consistent with previous reports, whereby the joint inactivation, either pharmacologically or genetically, of both cytochrome bcc and bd oxidases resulted in bactericidal effects on $M$. $t b$ in vitro and in vivo $[65,76,77,160]$. Exploiting the synthetic lethal interaction between these two terminal oxidases is an extremely attractive approach to eradicate $M$. $t b$. Inhibitors of this alternate terminal oxidase may have been missed in previous screens, which may be due to the fact that many screens have been performed under conditions in which the Cyt-bd is non-essential. In light of this, screening under stressed conditions may lead to the identification of Cyt-bd inhibitors amenable to chemical optimisation.

\subsection{Inhibitors of the $F_{1} F_{0}$ ATP Synthase}

The $\mathrm{F}_{1} \mathrm{~F}_{0}$ ATP synthase is a clinically-validated drug target in $M . t b$, since the approval of BDQ by the US FDA for the treatment of multi-drug resistant TB. The mechanism of action of BDQ has been extensively studied in mycobacteria [20,83,162-164]. Briefly, BDQ binds to the c-subunit and the $\varepsilon$-subunit of the ATP synthase by mimicking key residues in the proton transfer chain and blocking the rotary movement of the c-subunit during the catalysis of ATP $[165,166]$, disrupting a fundamental process for bacterial survival in both actively growing and non-growing states [20,162]. The inhibition of the ATP synthase leads to ATP depletion and also dissipation of the membrane potential, as BDQ was shown to have uncoupling properties mediated by the $\mathrm{H}+/ \mathrm{K}+$ antiporter [167]. Unfortunately, drug resistance to BDQ has already emerged in MDR-TB patients, with several 
mechanisms of resistance having been reported [27,168-170]. Predominantly, mutations in atpE, the transcriptional repressor of the MmpL5-MmpS5, and the coding region of this efflux pump have been identified in humans [170-173]. In light of the emergence of resistance and the cardiotoxicity (QT prolongation) associated with BDQ treatment [174], efforts are currently ongoing to develop optimised diarylquinoline analogues (Table 4). The development of BDQ analogues 3,5-dialkoxypyridines is particularly interesting [175-180]. The preclinical candidate of this series, TBAJ-876, is less cardiotoxic than BDQ and 10 times more potent [180]. Through the isolation of resistant mutants and NMR studies, TBAJ-876 was shown to target the c- and $\varepsilon$-subunits of the ATP synthase at the same binding site as BDQ, indicating that this new analogue retains the mechanism of action of BDQ [180]. Kumar et al. screened a set of 700 compounds from the CSIR-IIIM repository for inhibition of mycobacterial ATP synthase activity using IMVs of M. smeg, leading to the identification of two compounds, the thiazolidine 5228485 and the cyclohexanediones 5220632. Both compounds inhibited ATP synthesis in IMVs and had MICs in the low micromolar range [181]. These bactericidal compounds were active against drug-resistant $M$. $t b$ strains and non-replicating $M$. $t b$ without apparent cytotoxicity [181]. Mutants selected against each compound were cross-resistant to $\mathrm{BDQ}$, although resistance studies additionally suggest that these compounds may inhibit a secondary target besides the ATP synthase [181]. Further SAR and mechanistic studies are needed to fully understand the mechanism of action and for the development of these two new classes of ATP synthase inhibitors.

Table 4. Inhibitors of the ATP synthase discussed in this review.

Chemical Class Represented by Ref


Table 4. Cont.

\begin{tabular}{cclll}
\hline Chemical Class & Represented by & Ref \\
\hline Cyclohexanediones & 5220632 & Structure & \\
Squaramides & &
\end{tabular}

Squaramides were identified in the same screen as imidazo[1,2-a]pyridine ethers (IPE) (see section inhibitors of the Cyt-bcc-aa3) [127], with both compounds identified as inhibitors of ATP synthesis. Isolation of mutants resistant to squaramides revealed the presence of mutations in the $\alpha$ and c- subunits of the ATP synthase. Interestingly, these mutants showed no cross-resistance to BDQ, suggesting a different mode of interaction with the ATP synthase than BDQ. Docking analysis of the most potent squaramide derivative, $31 \mathrm{f}$ (MIC M. $t b 0.8 \mu \mathrm{M}$ ), showed that squaramides bind at the interface of the $\alpha$ and c-subunits of the ATP synthase. Compound 31f shows good accumulation in the serum in mice at a concentration above the MIC for over $15 \mathrm{~h}$ when administered with $100 \mathrm{mg} / \mathrm{kg}$ ABT, and was bacteriostatic in an acute model of TB. Further optimisation of the PK properties and in vivo safety is needed to advance this compound as a potential pre-clinical candidate for TB.

\section{6. $P M F$}

A wide range of compounds currently exists that target the PMF in bacteria, including rotenone which inhibits major proton pumps and protonophores (e.g., carbonyl cyanide m-chlorophenyl hydrazone, also known as CCCP), which translocate protons across the cell membranes [14] (Table 5). More specifically to mycobacteria, pyrazinoic acid, the active form of the first-line TB drug PZA, was demonstrated to decrease PMF and ATP levels in M. bovis BCG [182]. Several other compounds active against $M$. $t b$ including SQ109, BDQ and CFZ were also found to be multi-targeting by behaving as uncouplers in addition to targeting enzymes [183]. While such an intrinsic and critical characteristic of the ETC is highly attractive therapeutically, such an approach would necessitate identifying compounds that are specific to the perturbation of mycobacterial PMF.

Recently, 2-aminoimidazoles (2-AI), a class of molecules with anti-biofilm activity, was shown to revert drug tolerance in an in vitro $M$. $t b$ biofilm model [184]. This class of compounds potentiate the activity of $\beta$-lactams by altering protein secretion and lipid export, suggesting that 2 -AI may perturb membrane energization [185]. Derivative 2B8 rapidly depolarized the membrane potential of live M. smeg, and collapsed the $\triangle \mathrm{pH}$ generated by $M$. smeg IMVs energized with NADH, similar to CCCP and other mycobacterial uncouplers. In addition, a decrease in the OCR and intracellular ATP levels were observed in $M$. $t b$ upon exposure to $2 \mathrm{~B} 8$. Taken together, the perturbations of $2 \mathrm{~B} 8$ on the PMF, OCR and ATP synthesis validates its uncoupling activity in mycobacteria [184]. 
Table 5. Inhibitors of the mycobacterial proton motive force (PMF) discuss in this review.

\begin{tabular}{|c|c|c|c|}
\hline Chemical Class & Represented by & Structure & Ref \\
\hline Ethylenediamine & SQ109 & & {$[186,187]$} \\
\hline Pyrazinamide & & & [188] \\
\hline 2-Aminoimidazoles & 2B8 & & [184] \\
\hline
\end{tabular}

\subsection{Respiratory Poisoning}

$\mathrm{NO}$ is a key component of the innate immune response against intracellular pathogens like $M . t b$ [189]. Two drugs, PA-824 and DEL (OPC-67683), were shown to release NO when activated by the deazaflavin-dependant nitroreductase Ddn (rv3547) of $M . t b[10,190]$. PA-824 and DEL are bicyclic nitroimidazoles that are approved for the treatment of DR-TB as part of a drug combination. Both drugs kill replicating and non-replicating $M . t b$. Under aerobic conditions, PA-824 and DEL inhibit mycolic acid synthesis [191,192], whereas, under anaerobic conditions, Singh et al. identified that the release of NO correlated with the formation of des-nitroimidazole metabolites, leading to the antimicrobial activity of PA-824 [10]. Transcriptomic analysis of $M$. $t b$ treated with DEL and PA-824 revealed that respiratory poisoning by NO is fundamental for the activity of the drug in mycobacteria [193]. The transcriptomic profile of bacteria exposed to DEL and PA-824 is similar to potassium cyanide, a cytochrome c oxidase-specific inhibitor, which suggests that NO poisoning in $M$. $t b$ may lead to the inhibition of the terminal oxidases [190].

\section{Combinations Including ETC Inhibitors}

TB treatment relies on the combination of several antibacterial agents. New regimens for TB need to be (1) effective against DS- and DR-TB, (2) contain drugs with new mechanisms of action, (3) are suitable for oral administration, and (4) do not interfere with drugs used to treat chronic conditions or chronic infections [194]. An effective regimen should combine drugs that preserve or even potentiate their activity (additivity or synergism) when given as a regimen. Due to their ability to perturb the energy metabolism of replicating and non-replicating $M$. $t b$, including drugs that target the ETC may shorten treatments against DS- and DR-TB. The recent approval of the BPaL regimen (BDQ-PA824-Linezolid; Nix-TB trial) for DR-TB highlights that inhibiting components of the ETC is key in developing new regimens against $M$. $t b$, even though the relative contribution of each drug to the sterilizing potency of the $\mathrm{BPaL}$ regimen remains to be further investigated in humans.

Several inhibitors in lead optimisation were tested in combination with other anti-TB drugs. $\mathrm{PAB}$, a Cyt-bcc oxidase inhibitor, resulted in the synergistic killing of $M$. $t b$ under both replicating and non-replicating conditions when combined with CFZ [195]. PABs in combination with BDQ demonstrated antagonism at early time points, particularly under non-replicating conditions. However, this antagonistic effect disappeared within three weeks, with PAB-BDQ combinations becoming highly bactericidal [195]. The specificity of the PAB series needs to be further studied since it kills nutrient-starved $M$. $t b$ while remaining bacteriostatic against replicating mycobacteria, a property 
not shared with other specific Cyt-bcc inhibitors [130,153]. A MenA inhibitor, NM-4, was synergistic even at low doses together with sub-bactericidal concentrations of BDQ, CFZ, and the QcrB inhibitor ND-10885 [196], causing enhanced and efficient killing of $M$. t $b$ in a time-kill curve assay [117]. These preliminary results underline the need to assess the efficacy of candidates in combination for TB therapy in an early stage of development.

Several ETC inhibitors are currently in ongoing pre-clinical and clinical trials to assess their efficacy against TB as part of new regimens [11]. These include BDQ, TBAJ-587 and TBAJ-876 (ATP synthase inhibitors), the first-line anti-TB drug PZA and SQ109 (inhibitors of the PMF), CFZ and its analogue TBI-166, and Q203 (inhibitor of Cyt-bcc-aa3 oxidase) [11]. SQ109 was reported to enhance the activity of anti-tuberculosis drugs INH, RIF and BDQ, and to shorten the time required to cure $M$. $t b$-infected mice [197]. Additionally, several inhibitors of the ETC compounds have a multi-target activity against the bacilli. The uncoupling effects of SQ109, PZA, BDQ, and CFZ suggest that these inhibitors may have a critical role due to their multi-targeting activity and should be taken into consideration for the further development of regimens against $M$. $t b$, particularly against DR-TB [183]. Assessing the in vitro or in vivo combinatory effects with repurposed or approved drugs for the treatment of TB has been another fruitful avenue to find new potential regimens comprising drug candidates that target the ETC. An example is TBI-166, an analogue of clofazimine with excellent potency alone or in combination with BDQ, PZA and linezolid in vitro and in vivo [198].

Q203 and BDQ were the first-in-class, orally-available representatives of the Cyt-bcc-aa3 and ATP synthase inhibitors, respectively. Q203 is currently in Phase $2 \mathrm{~b}$ clinical trials and demonstrated potency in a 14-day, proof-of-concept design study of early bactericidal activity. It was safe and well-tolerated throughout the different dose strengths (100, 200 and $300 \mathrm{mg}$ ). Preliminary studies in vivo using a mouse footpad infection model of Buruli ulcer (M. ulcerans) showed that the addition of Q203 to the two-drug regimen of RIF and CFZ, or the three-drug regimen rifamycin, CFZ, and BDQ can decrease the treatment duration from four to two weeks, without any relapse after 12 weeks from the completion of treatment [199]. A similar approach could be developed to find an effective Q203-based regimen against $M$. $t b$ with the addition of a chemical inhibitor of the Cyt-bd. Nonetheless, the plasticity and the possible re-routing of the mycobacterial ETC through chemical inhibition can be used against mycobacteria to conceive an effective regimen. Bioenergetics and ex vivo efficacy studies revealed that a combination of BDQ, CFZ and Q203 killed $M$. tb synergistically, with BDQ and Q203 potentiating CFZ's ROS production [158]. These results suggest that the potentiation of Q203 can be achieved without a Cyt-bd oxidase inhibitor as well.

With the number of BDQ-containing regimens undergoing clinical trials, BDQ seems a drug of choice for further development of TB therapy. Several Phase 1 and 2 clinical trials which include BDQ are currently in progress [194]. However, the emergence of resistance and its high cardiotoxicity may jeopardize the potency of this antitubercular drug. The development of new ATP synthase inhibitors that harbour less cardiotoxicity and are potentially less prone to the development of resistance, such as TBAJ-876 and TBAJ-587, will most likely lead to the development of new regimens including these second generation of diaryquinolines $[179,180]$.

\section{Conclusions and Perspectives}

This review has highlighted the current efforts made to find new inhibitors against components of the ETC. To date, tackling the mycobacterial OxPhos pathway has been a prolific avenue in finding new inhibitors against $M$. $t b$, as well as other mycobacteria such as $M$. ulcerans. Deciphering the role of each new scaffold targeting ETC components will enable a further understanding of this pivotal pathway in $M$. tb survival and metabolism. Several components are still poorly exploited as potential targets for chemical inhibition, either due to their homology to eukaryotic components or their regulation as a specific bacterial response to the environment/stress (e.g., Cyt-bd). Redundancy of several components of the ETC further complicates the establishment of a background regimen comprising of ETC inhibitors. A deeper understanding of the intricately-linked energy metabolism processes would be required to 
target the various metabolic pathways which $M$. $t b$ can reroute to, such that a successful regimen can be developed. Most screens to identify inhibitors of the OxPhos have been conducted using whole-cell assays, target-based assays or phenotypic screening using ATP as a readout. However, these screening methods may not be suitable for the identification of inhibitors of some components such as the Cyt-bd, which are conditionally essential under specific conditions. Therefore, a better understanding of the modulation of the ETC under the host physiological conditions encountered by $M$. $t b$ would be of great interest for further development of energy metabolism inhibitors. Lastly, ETC inhibitors have the potential to revolutionise future TB treatments by contributing to efficacious regimens which are simpler and shorter, as evident from BDQ's role in the novel, three-drug, all-oral BPaL regimen.

Author Contributions: Conceptualization, C.S.-Y.F., K.P. and A.L.; writing-original draft preparation, C.S.-Y.F., K.P. and A.L.; writing-review and editing, C.S.-Y.F., K.P. and A.L.; visualization, C.S.-Y.F. and A.L.; project administration, K.P. and A.L.; funding acquisition, K.P. All authors have read and agreed to the published version of the manuscript.

Funding: This work was supported in part by the National Research Foundation (NRF) Singapore, NRF Competitive Research Programme (CRP), Grant Award Number NRF-CRP18-2017-01 (K.P.)

Acknowledgments: We would like to thank Marcel Behr and Jean-Yves Dubé for their contributions to the revision of the manuscript.

Conflicts of Interest: The authors declare no conflict of interest. The funders had no role in the design of the study; in the collection, analyses, or interpretation of data; in the writing of the manuscript, or in the decision to publish the results

\section{References}

1. WHO |Global Tuberculosis Report 2019. Available online: http://www.who.int/tb/publications/global_report/ en/ (accessed on 17 February 2020).

2. McKinney, J.D. In vivo veritas: The search for TB drug targets goes live. Nat. Med. 2000, 6, 1330-1333. [CrossRef] [PubMed]

3. WHO | WHO Consolidated Guidelines on Drug-Resistant Tuberculosis Treatment. Available online: http://www.who.int/tb/publications/2019/consolidated-guidelines-drug-resistant-TB-treatment/en/ (accessed on 17 February 2020).

4. Sotgiu, G.; Centis, R.; D'ambrosio, L.; Migliori, G.B. Tuberculosis treatment and drug regimens. Cold Spring Harb. Perspect. Med. 2015, 5, a017822. [CrossRef] [PubMed]

5. Borisov, S.; Danila, E.; Maryandyshev, A.; Dalcolmo, M.; Miliauskas, S.; Kuksa, L.; Manga, S.; Skrahina, A.; Diktanas, S.; Codecasa, L.R.; et al. Surveillance of adverse events in the treatment of drug-resistant tuberculosis: First global report. Eur. Respir. J. 2019, 54, 1901522. [CrossRef] [PubMed]

6. Akkerman, O.; Aleksa, A.; Alffenaar, J.-W.; Al-Marzouqi, N.H.; Arias-Guillén, M.; Belilovski, E.; Bernal, E.; Boeree, M.J.; Borisov, S.E.; Bruchfeld, J.; et al. Surveillance of adverse events in the treatment of drug-resistant tuberculosis: A global feasibility study. Int. J. Infect. Dis. 2019, 83, 72-76. [CrossRef]

7. Janssen Therapeutics, Division of Janssen Products, LP. (2019) Sirturo ®: HIGHLIGHTS OF PRESCRIBING INFORMATION. Available online: https://www.accessdata.fda.gov/drugsatfda_docs/label/ 2019/204384s010lbl.pdf (accessed on 26 March 2020).

8. European Medicines Agency-Find Medicine-Deltyba. Available online: http://www.ema.europa.eu/ema/index. jsp?curl=pages/medicines/human/medicines/002552/human_med_001699.jsp\&mid=WC0b01ac058001d124 (accessed on 31 May 2018).

9. U.S. Food and Drug Administration FDA Approves New Drug for Treatment-Resistant Forms of Tuberculosis that Affects the Lungs. Available online: http://www.fda.gov/news-events/press-announcements/fdaapproves-new-drug-treatment-resistant-forms-tuberculosis-affects-lungs (accessed on 31 January 2020).

10. Singh, R.; Manjunatha, U.; Boshoff, H.I.M.; Ha, Y.H.; Niyomrattanakit, P.; Ledwidge, R.; Dowd, C.S.; Lee, I.Y.; Kim, P.; Zhang, L.; et al. PA-824 kills nonreplicating Mycobacterium tuberculosis by intracellular NO release. Science 2008, 322, 1392-1395. [CrossRef]

11. Pipeline | Working Group for New TB Drugs. Available online: https://www.newtbdrugs.org/pipeline/clinical (accessed on 17 February 2020). 
12. Pethe, K.; Bifani, P.; Jang, J.; Kang, S.; Park, S.; Ahn, S.; Jiricek, J.; Jung, J.; Jeon, H.K.; Cechetto, J.; et al. Discovery of Q203, a potent clinical candidate for the treatment of tuberculosis. Nat. Med. 2013, 19, 1157-1160. [CrossRef]

13. Bald, D.; Villellas, C.; Lu, P.; Koul, A. Targeting energy metabolism in mycobacterium tuberculosis, a new paradigm in antimycobacterial drug discovery. mBio 2017, 8, e00272-17. [CrossRef]

14. Cook, G.M.; Hards, K.; Dunn, E.; Heikal, A.; Nakatani, Y.; Greening, C.; Crick, D.C.; Fontes, F.L.; Pethe, K.; Hasenoehrl, E.; et al. Oxidative phosphorylation as a target space for tuberculosis: Success, caution, and future directions. Microbiol. Spectr. 2017, 5. [CrossRef]

15. Matsoso, L.G.; Kana, B.D.; Crellin, P.K.; Lea-Smith, D.J.; Pelosi, A.; Powell, D.; Dawes, S.S.; Rubin, H.; Coppel, R.L.; Mizrahi, V. Function of the cytochrome bc1-aa3 branch of the respiratory network in mycobacteria and network adaptation occurring in response to its disruption. J. Bacteriol. 2005, 187, 6300-6308. [CrossRef]

16. Billig, S.; Schneefeld, M.; Huber, C.; Grassl, G.A.; Eisenreich, W.; Bange, F.-C. Lactate oxidation facilitates growth of Mycobacterium tuberculosis in human macrophages. Sci. Rep. 2017, 7, 6484. [CrossRef] [PubMed]

17. Cole, S.T.; Brosch, R. Deciphering the biology of Mycobacterium tuberculosis from the complete genome sequence. Trends Biochem. Sci. 1997, 22, 28-31.

18. Boshoff, H.I.M.; Barry 3rd, C.E. Tuberculosis-Metabolism and respiration in the absence of growth. Nat. Rev. Microbiol. 2005, 3, 70-80. [CrossRef] [PubMed]

19. Rao, S.P.S.; Alonso, S.; Rand, L.; Dick, T.; Pethe, K. The protonmotive force is required for maintaining ATP homeostasis and viability of hypoxic, nonreplicating mycobacterium tuberculosis. Proc. Natl. Acad. Sci. USA 2008, 105, 11945-11950. [CrossRef] [PubMed]

20. Koul, A.; Vranckx, L.; Dendouga, N.; Balemans, W.; den Wyngaert, I.V.; Vergauwen, K.; Göhlmann, H.W.H.; Willebrords, R.; Poncelet, A.; Guillemont, J.; et al. Diarylquinolines are bactericidal for dormant mycobacteria as a result of disturbed ATP homeostasis. J. Biol. Chem. 2008, 283, 25273-25280. [CrossRef] [PubMed]

21. Gengenbacher, M.; Rao, S.P.S.; Pethe, K.; Dick, T. Nutrient-starved, non-replicating Mycobacterium tuberculosis requires respiration, ATP synthase and isocitrate lyase for maintenance of ATP homeostasis and viability. Microbiol. Read. Engl. 2010, 156, 81-87. [CrossRef] [PubMed]

22. Adams, K.N.; Takaki, K.; Connolly, L.E.; Wiedenhoft, H.; Winglee, K.; Humbert, O.; Edelstein, P.H.; Cosma, C.L.; Ramakrishnan, L. Drug tolerance in replicating mycobacteria mediated by a macrophageinduced efflux mechanism. Cell 2011, 145, 39-53. [CrossRef]

23. Machado, D.; Couto, I.; Perdigão, J.; Rodrigues, L.; Portugal, I.; Baptista, P.; Veigas, B.; Amaral, L.; Viveiros, M. Contribution of efflux to the emergence of isoniazid and multidrug resistance in Mycobacterium tuberculosis. PLoS ONE 2012, 7, e34538. [CrossRef]

24. Adams, K.N.; Szumowski, J.D.; Ramakrishnan, L. Verapamil, and its metabolite norverapamil, inhibit macrophage-induced, bacterial efflux pump-mediated tolerance to multiple anti-tubercular drugs. J. Infect. Dis. 2014, 210, 456-466. [CrossRef]

25. Coelho, T.; Machado, D.; Couto, I.; Maschmann, R.; Ramos, D.; von Groll, A.; Rossetti, M.L.; Silva, P.A.; Viveiros, M. Enhancement of antibiotic activity by efflux inhibitors against multidrug resistant Mycobacterium tuberculosis clinical isolates from Brazil. Front. Microbiol. 2015, 6, 330. [CrossRef]

26. Li, G.; Zhang, J.; Guo, Q.; Jiang, Y.; Wei, J.; Zhao, L.; Zhao, X.; Lu, J.; Wan, K. Efflux pump gene expression in multidrug-resistant Mycobacterium tuberculosis clinical isolates. PLoS ONE 2015, 10, e0119013. [CrossRef] [PubMed]

27. Andries, K.; Villellas, C.; Coeck, N.; Thys, K.; Gevers, T.; Vranckx, L.; Lounis, N.; de Jong, B.C.; Koul, A. Acquired resistance of Mycobacterium tuberculosis to bedaquiline. PLoS ONE 2014, 9, e102135. [CrossRef] [PubMed]

28. Weinstein, E.A.; Yano, T.; Li, L.-S.; Avarbock, D.; Avarbock, A.; Helm, D.; McColm, A.A.; Duncan, K.; Lonsdale, J.T.; Rubin, H. Inhibitors of type II NADH:menaquinone oxidoreductase represent a class of antitubercular drugs. Proc. Natl. Acad. Sci. USA 2005, 102, 4548-4553. [CrossRef] [PubMed]

29. Harbut, M.B.; Yang, B.; Liu, R.; Yano, T.; Vilchèze, C.; Cheng, B.; Lockner, J.; Guo, H.; Yu, C.; Franzblau, S.G.; et al. Small molecules targeting mycobacterium tuberculosis Type II NADH dehydrogenase exhibit antimycobacterial activity. Angew. Chem. Int. Ed. Engl. 2018, 57, 3478-3482. [CrossRef] [PubMed] 
30. Murugesan, D.; Ray, P.C.; Bayliss, T.; Prosser, G.A.; Harrison, J.R.; Green, K.; Soares de Melo, C.; Feng, T.-S.; Street, L.J.; Chibale, K.; et al. 2-Mercapto-Quinazolinones as inhibitors of Type II NADH Dehydrogenase and Mycobacterium tuberculosis: Structure-activity relationships, mechanism of action and absorption, distribution, metabolism, and excretion characterization. ACS Infect. Dis. 2018, 4, 954-969. [CrossRef] [PubMed]

31. Sassetti, C.M.; Boyd, D.H.; Rubin, E.J. Genes required for mycobacterial growth defined by high density mutagenesis. Mol. Microbiol. 2003, 48, 77-84. [CrossRef] [PubMed]

32. Griffin, J.E.; Gawronski, J.D.; Dejesus, M.A.; Ioerger, T.R.; Akerley, B.J.; Sassetti, C.M. High-resolution phenotypic profiling defines genes essential for mycobacterial growth and cholesterol catabolism. PLoS Pathog. 2011, 7, e1002251. [CrossRef]

33. DeJesus, M.A.; Gerrick, E.R.; Xu, W.; Park, S.W.; Long, J.E.; Boutte, C.C.; Rubin, E.J.; Schnappinger, D.; Ehrt, S.; Fortune, S.M.; et al. Comprehensive essentiality analysis of the mycobacterium tuberculosis genome via saturating transposon mutagenesis. mBio 2017, 8, e02133-16. [CrossRef]

34. Vilchèze, C.; Weinrick, B.; Leung, L.W.; Jacobs, W.R. Plasticity of Mycobacterium tuberculosis NADH dehydrogenases and their role in virulence. Proc. Natl. Acad. Sci. USA 2018, 115, 1599-1604. [CrossRef]

35. Beites, T.; O’Brien, K.; Tiwari, D.; Engelhart, C.A.; Walters, S.; Andrews, J.; Yang, H.-J.; Sutphen, M.L.; Weiner, D.M.; Dayao, E.K.; et al. Plasticity of the mycobacterium tuberculosis respiratory chain and its impact on tuberculosis drug development. Nat. Commun. 2019, 10, 4970. [CrossRef]

36. Maklashina, E.; Cecchini, G.; Dikanov, S.A. Defining a direction: Electron transfer and catalysis in Escherichia coli complex II enzymes. Biochim. Biophys. Acta 2013, 1827, 668-678. [CrossRef] [PubMed]

37. Hards, K.; Adolph, C.; Harold, L.K.; McNeil, M.B.; Cheung, C.-Y.; Jinich, A.; Rhee, K.Y.; Cook, G.M. Two for the price of one: Attacking the energetic-metabolic hub of mycobacteria to produce new chemotherapeutic agents. Prog. Biophys. Mol. Biol. 2019, S0079610719302111. [CrossRef] [PubMed]

38. Rutter, J.; Winge, D.R.; Schiffman, J.D. Succinate dehydrogenase-Assembly, regulation and role in human disease. Mitochondrion 2010, 10, 393-401. [CrossRef] [PubMed]

39. Cook, G.M.; Hards, K.; Vilchèze, C.; Hartman, T.; Berney, M. Energetics of respiration and oxidative phosphorylation in mycobacteria. Microbiol. Spectr. 2014, 2, 389-409. [CrossRef] [PubMed]

40. Baek, S.-H.; Li, A.H.; Sassetti, C.M. Metabolic regulation of mycobacterial growth and antibiotic sensitivity. PLoS Biol. 2011, 9, e1001065. [CrossRef] [PubMed]

41. Hartman, T.; Weinrick, B.; Vilchèze, C.; Berney, M.; Tufariello, J.; Cook, G.M.; Jacobs, W.R.J., Jr. Succinate Dehydrogenase is the Regulator of Respiration in Mycobacterium tuberculosis. PLoS Pathog. 2014, 10, e1004510. [CrossRef]

42. Lemos, R.S.; Fernandes, A.S.; Pereira, M.M.; Gomes, C.M.; Teixeira, M. Quinol:fumarate oxidoreductases and succinate:quinone oxidoreductases: Phylogenetic relationships, metal centres and membrane attachment. Biochim. Biophys. Acta 2002, 1553, 158-170. [CrossRef]

43. Pecsi, I.; Hards, K.; Ekanayaka, N.; Berney, M.; Hartman, T.; Jacobs, W.R.; Cook, G.M. Essentiality of succinate dehydrogenase in mycobacterium smegmatis and its role in the generation of the membrane potential under hypoxia. mBio 2014, 5, e01093-14. [CrossRef]

44. Collins, M.D.; Jones, D. Distribution of isoprenoid quinone structural types in bacteria and their taxonomic implication. Microbiol. Rev. 1981, 45, 316-354. [CrossRef]

45. Meganathan, R. Biosynthesis of menaquinone (vitamin K2) and ubiquinone (coenzyme Q): A perspective on enzymatic mechanisms. In Vitamins \& Hormones; Cofactor Biosynthesis; Academic Press: Cambridge, MA, USA, 2001; Volume 61, pp. 173-218.

46. Dhiman, R.K.; Mahapatra, S.; Slayden, R.A.; Boyne, M.E.; Lenaerts, A.; Hinshaw, J.C.; Angala, S.K.; Chatterjee, D.; Biswas, K.; Narayanasamy, P.; et al. Menaquinone synthesis is critical for maintaining mycobacterial viability during exponential growth and recovery from non-replicating persistence. Mol. Microbiol. 2009, 72, 85-97. [CrossRef]

47. Kurosu, M.; Crick, D. MenA is a promising drug target for developing novel lead molecules to combat mycobacterium tuberculosis. Med. Chem. 2009, 5, 197-207. [CrossRef] [PubMed]

48. Li, X.; Liu, N.; Zhang, H.; Knudson, S.E.; Li, H.-J.; Lai, C.-T.; Simmerling, C.; Slayden, R.A.; Tonge, P.J. CoA Adducts of 4-Oxo-4-phenylbut-2-enoates: Inhibitors of MenB from the M. tuberculosis Menaquinone Biosynthesis Pathway. ACS Med. Chem. Lett. 2011, 2, 818-823. [CrossRef] [PubMed] 
49. Debnath, J.; Siricilla, S.; Wan, B.; Crick, D.C.; Lenaerts, A.J.; Franzblau, S.G.; Kurosu, M. Discovery of selective menaquinone biosynthesis inhibitors against Mycobacterium tuberculosis. J. Med. Chem. 2012, 55, 3739-3755. [CrossRef] [PubMed]

50. Lu, X.; Zhang, H.; Tonge, P.J.; Tan, D.S. Mechanism-based inhibitors of MenE, an acyl-CoA synthetase involved in bacterial menaquinone biosynthesis. Bioorg. Med. Chem. Lett. 2008, 18, 5963-5966. [CrossRef]

51. Sukheja, P.; Kumar, P.; Mittal, N.; Li, S.-G.; Singleton, E.; Russo, R.; Perryman, A.L.; Shrestha, R.; Awasthi, D.; Husain, S.; et al. A novel small-molecule inhibitor of the mycobacterium tuberculosis demethylmenaquinone methyltransferase meng is bactericidal to both growing and nutritionally deprived persister cells. mBio 2017, 8, e02022-16. [CrossRef]

52. Truglio, J.J.; Theis, K.; Feng, Y.; Gajda, R.; Machutta, C.; Tonge, P.J.; Kisker, C. Crystal structure of Mycobacterium tuberculosis MenB, a key enzyme in vitamin K2 biosynthesis. J. Biol. Chem. 2003, 278, 42352-42360. [CrossRef]

53. Morand, O.H.; Aebi, J.D.; Dehmlow, H.; Ji, Y.H.; Gains, N.; Lengsfeld, H.; Himber, J. Ro 48-8.071, a new 2,3-oxidosqualene:lanosterol cyclase inhibitor lowering plasma cholesterol in hamsters, squirrel monkeys, and minipigs: Comparison to simvastatin. J. Lipid Res. 1997, 38, 373-390.

54. Goldman, R.C. Why are membrane targets discovered by phenotypic screens and genome sequencing in Mycobacterium tuberculosis? Tuberc. Edinb. Scotl. 2013, 93, 569-588. [CrossRef]

55. Megehee, J.A.; Hosler, J.P.; Lundrigan, M.D. Evidence for a cytochrome bcc-aa3 interaction in the respiratory chain of Mycobacterium smegmatis. Microbiol. Read. Engl. 2006, 152, 823-829. [CrossRef]

56. Kim, M.-S.; Jang, J.; Ab Rahman, N.B.; Pethe, K.; Berry, E.A.; Huang, L.-S. Isolation and characterization of a hybrid respiratory supercomplex consisting of mycobacterium tuberculosis cytochrome bcc and mycobacterium smegmatis cytochrome aa3. J. Biol. Chem. 2015, 290, 14350-14360. [CrossRef]

57. Gong, H.; Li, J.; Xu, A.; Tang, Y.; Ji, W.; Gao, R.; Wang, S.; Yu, L.; Tian, C.; Li, J.; et al. An electron transfer path connects subunits of a mycobacterial respiratory supercomplex. Science 2018, 362, eaat8923. [CrossRef] [PubMed]

58. Wiseman, B.; Nitharwal, R.G.; Fedotovskaya, O.; Schäfer, J.; Guo, H.; Kuang, Q.; Benlekbir, S.; Sjöstrand, D.; Ädelroth, P.; Rubinstein, J.L.; et al. Structure of a functional obligate complex III 2 IV 2 respiratory supercomplex from Mycobacterium smegmatis. Nat. Struct. Mol. Biol. 2018, 25, 1128-1136. [CrossRef] [PubMed]

59. Borisov, V.B.; Gennis, R.B.; Hemp, J.; Verkhovsky, M.I. The cytochrome bd respiratory oxygen reductases. Biochim. Biophys. Acta 2011, 1807, 1398-1413. [CrossRef] [PubMed]

60. Allen, R.J.; Brenner, E.P.; VanOrsdel, C.E.; Hobson, J.J.; Hearn, D.J.; Hemm, M.R. Conservation analysis of the CydX protein yields insights into small protein identification and evolution. BMC Genom. 2014, 15, 946. [CrossRef] [PubMed]

61. Poole, R.K.; Hatch, L.; Cleeter, M.W.J.; Gibson, F.; Cox, G.B.; Wu, G. Cytochrome bd biosynthesis in Escherichia coli: The sequences of the cydC and cydD genes suggest that they encode the components of an $\mathrm{ABC}$ membrane transporter. Mol. Microbiol. 1993, 10, 421-430. [CrossRef]

62. Shepherd, M. The CydDC ABC transporter of Escherichia coli: New roles for a reductant efflux pump. Biochem. Soc. Trans. 2015, 43, 908-912. [CrossRef]

63. Mascolo, L.; Bald, D. Cytochrome bd in Mycobacterium tuberculosis: A respiratory chain protein involved in the defense against antibacterials. Prog. Biophys. Mol. Biol. 2019. [CrossRef]

64. Berney, M.; Hartman, T.E.; Jacobs, W.R. A Mycobacterium tuberculosis Cytochrome bd Oxidase Mutant Is Hypersensitive to Bedaquiline. mBio 2014, 5, e01275-14. [CrossRef]

65. Kalia, N.P.; Hasenoehrl, E.J.; Rahman, N.B.A.; Koh, V.H.; Ang, M.L.T.; Sajorda, D.R.; Hards, K.; Grüber, G.; Alonso, S.; Cook, G.M.; et al. Exploiting the synthetic lethality between terminal respiratory oxidases to kill Mycobacterium tuberculosis and clear host infection. Proc. Natl. Acad. Sci. USA 2017, 114, 7426-7431. [CrossRef]

66. Safarian, S.; Rajendran, C.; Müller, H.; Preu, J.; Langer, J.D.; Ovchinnikov, S.; Hirose, T.; Kusumoto, T.; Sakamoto, J.; Michel, H. Structure of a bd oxidase indicates similar mechanisms for membrane-integrated oxygen reductases. Science 2016, 352, 583-586. [CrossRef]

67. Safarian, S.; Hahn, A.; Mills, D.J.; Radloff, M.; Eisinger, M.L.; Nikolaev, A.; Meier-Credo, J.; Melin, F.; Miyoshi, H.; Gennis, R.B.; et al. Active site rearrangement and structural divergence in prokaryotic respiratory oxidases. Science 2019, 366, 100-104. [CrossRef] [PubMed] 
68. Lee, B.S.; Sviriaeva, E.; Pethe, K. Targeting the cytochrome oxidases for drug development in mycobacteria. Prog. Biophys. Mol. Biol. 2020. [CrossRef] [PubMed]

69. D'mello, R.; Hill, S.; Poole, R.K. The cytochrome bd quinol oxidase in Escherichia coli has an extremely high oxygen affinity and two oxygen-binding haems: Implications for regulation of activity in vivo by oxygen inhibition. Microbiology 1996, 142, 755-763. [CrossRef] [PubMed]

70. Miller, M.J.; Gennis, R.B. The cytochrome d complex is a coupling site in the aerobic respiratory chain of Escherichia coli. J. Biol. Chem. 1985, 260, 14003-14008. [PubMed]

71. Jasaitis, A.; Borisov, V.B.; Belevich, N.P.; Morgan, J.E.; Konstantinov, A.A.; Verkhovsky, M.I. Electrogenic reactions of cytochrome bd. Biochemistry 2000, 39, 13800-13809. [CrossRef]

72. Gopinath, V.; Raghunandanan, S.; Gomez, R.L.; Jose, L.; Surendran, A.; Ramachandran, R.; Pushparajan, A.R.; Mundayoor, S.; Jaleel, A.; Kumar, R.A. Profiling the proteome of mycobacterium tuberculosis during dormancy and reactivation. Mol. Cell. Proteom. 2015, 14, 2160-2176. [CrossRef]

73. Cortes, T.; Schubert, O.T.; Banaei-Esfahani, A.; Collins, B.C.; Aebersold, R.; Young, D.B. Delayed effects of transcriptional responses in Mycobacterium tuberculosis exposed to nitric oxide suggest other mechanisms involved in survival. Sci. Rep. 2017, 7, 1-9. [CrossRef]

74. Shi, L.; Sohaskey, C.D.; Kana, B.D.; Dawes, S.; North, R.J.; Mizrahi, V.; Gennaro, M.L. Changes in energy metabolism of Mycobacterium tuberculosis in mouse lung and under in vitro conditions affecting aerobic respiration. Proc. Natl. Acad. Sci. USA 2005, 102, 15629-15634. [CrossRef]

75. Arora, K.; Ochoa-Montano, B.; Tsang, P.S.; Blundell, T.L.; Dawes, S.S.; Mizrahi, V.; Bayliss, T.; Mackenzie, C.J.; Cleghorn, L.A.T.; Ray, P.C.; et al. Respiratory flexibility in response to inhibition of cytochrome c oxidase in mycobacterium tuberculosis. Antimicrob. Agents Chemother. 2014, 58, 6962-6965. [CrossRef]

76. Foo, C.S.; Lupien, A.; Kienle, M.; Vocat, A.; Benjak, A.; Sommer, R.; Lamprecht, D.A.; Steyn, A.J.C.; Pethe, K.; Piton, J.; et al. Arylvinylpiperazine Amides, a New Class of Potent Inhibitors Targeting QcrB of Mycobacterium tuberculosis. mBio 2018, 9. [CrossRef]

77. Lupien, A.; Foo, C.S.-Y.; Savina, S.; Vocat, A.; Piton, J.; Monakhova, N.; Benjak, A.; Lamprecht, D.A.; Steyn, A.J.C.; Pethe, K.; et al. New 2-Ethylthio-4-methylaminoquinazoline derivatives inhibiting two subunits of cytochrome bc1 in Mycobacterium tuberculosis. PLoS Pathog. 2020, 16, e1008270. [CrossRef] [PubMed]

78. Lu, P.; Lill, H.; Bald, D. ATP synthase in mycobacteria: Special features and implications for a function as drug target. Biochim. Biophys. Acta BBA-Bioenerg. 2014, 1837, 1208-1218. [CrossRef] [PubMed]

79. Walker, J.E. The ATP synthase: The understood, the uncertain and the unknown. Biochem. Soc. Trans. 2013, 41, 1-16. [CrossRef] [PubMed]

80. von Ballmoos, C.; Cook, G.M.; Dimroth, P. Unique rotary atp synthase and its biological diversity. Annu. Rev. Biophys. 2008, 37, 43-64. [CrossRef]

81. Higashi, T.; Kalra, V.K.; Lee, S.H.; Bogin, E.; Brodie, A.F. Energy-transducing membrane-bound coupling factor-ATPase from Mycobacterium phlei. I. Purification, homogeneity, and properties. J. Biol. Chem. 1975, 250, 6541-6548.

82. Haagsma, A.C.; Driessen, N.N.; Hahn, M.-M.; Lill, H.; Bald, D. ATP synthase in slow- and fast-growing mycobacteria is active in ATP synthesis and blocked in ATP hydrolysis direction. FEMS Microbiol. Lett. 2010, 313, 68-74. [CrossRef]

83. Andries, K.; Verhasselt, P.; Guillemont, J.; Göhlmann, H.W.H.; Neefs, J.-M.; Winkler, H.; Gestel, J.V.; Timmerman, P.; Zhu, M.; Lee, E.; et al. A Diarylquinoline drug active on the ATP synthase of mycobacterium tuberculosis. Science 2005, 307, 223-227. [CrossRef]

84. Bald, D.; Koul, A. Respiratory ATP synthesis: The new generation of mycobacterial drug targets? FEMS Microbiol. Lett. 2010, 308, 1-7. [CrossRef]

85. Zhang, A.T.; Montgomery, M.G.; Leslie, A.G.W.; Cook, G.M.; Walker, J.E. The structure of the catalytic domain of the ATP synthase from Mycobacterium smegmatis is a target for developing antitubercular drugs. Proc. Natl. Acad. Sci. USA 2019, 116, 4206-4211. [CrossRef]

86. Joon, S.; Ragunathan, P.; Sundararaman, L.; Nartey, W.; Kundu, S.; Manimekalai, M.S.S.; Bogdanović, N.; Dick, T.; Grüber, G. The NMR solution structure of Mycobacterium tuberculosis F- ATP synthase subunit $\varepsilon$ provides new insight into energy coupling inside the rotary engine. FEBS J. 2018, 285, 1111-1128. [CrossRef] 
87. Saw, W.-G.; Wu, M.-L.; Ragunathan, P.; Biuković, G.; Lau, A.-M.; Shin, J.; Harikishore, A.; Cheung, C.-Y.; Hards, K.; Sarathy, J.P.; et al. Disrupting coupling within mycobacterial F-ATP synthases subunit $\varepsilon$ causes dysregulated energy production and cell wall biosynthesis. Sci. Rep. 2019, 9, 1-15. [CrossRef] [PubMed]

88. Hotra, A.; Suter, M.; Biuković, G.; Ragunathan, P.; Kundu, S.; Dick, T.; Grüber, G. Deletion of a unique loop in the mycobacterial F-ATP synthase $\gamma$ subunit sheds light on its inhibitory role in ATP hydrolysis-driven $\mathrm{H}+$ pumping. FEBS J. 2016, 283, 1947-1961. [CrossRef] [PubMed]

89. Ragunathan, P.; Sielaff, H.; Sundararaman, L.; Biuković, G.; Manimekalai, M.S.S.; Singh, D.; Kundu, S.; Wohland, T.; Frasch, W.; Dick, T.; et al. The uniqueness of subunit $\alpha$ of mycobacterial F-ATP synthases: An evolutionary variant for niche adaptation. J. Biol. Chem. 2017, 292, 11262-11279. [CrossRef] [PubMed]

90. Kinoshita, N.; Unemoto, T.; Kobayashi, H. Proton motive force is not obligatory for growth of Escherichia coli. J. Bacteriol. 1984, 160, 1074-1077. [CrossRef] [PubMed]

91. Melo, A.M.P.; Bandeiras, T.M.; Teixeira, M. New insights into type II NAD (P) H:quinone oxidoreductases. Microbiol. Mol. Biol. Rev. 2004, 68, 603-616. [CrossRef]

92. Yano, T.; Kassovska-Bratinova, S.; Teh, J.S.; Winkler, J.; Sullivan, K.; Isaacs, A.; Schechter, N.M.; Rubin, H. Reduction of clofazimine by mycobacterial type $2 \mathrm{NADH}$ : Quinone oxidoreductase: A pathway for the generation of bactericidal levels of reactive oxygen species. J. Biol. Chem. 2011, 286, 10276-10287. [CrossRef]

93. Xu, J.; Wang, B.; Fu, L.; Zhu, H.; Guo, S.; Huang, H.; Yin, D.; Zhang, Y.; Lu, Y. In vitro and in vivo activities of the Riminophenazine TBI-166 against Mycobacterium tuberculosis. Antimicrob. Agents Chemother. 2019, 63, e02155-18. [CrossRef]

94. Bourdon, J.L. Contribution to the study of the antibiotic properties of chlorpromazine or 4560 RP. Ann. Inst. Pasteur 1961, 101, 876-886.

95. Amaral, L.; Kristiansen, J.E.; Abebe, L.S.; Millett, W. Inhibition of the respiration of multi-drug resistant clinical isolates of Mycobacterium tuberculosis by thioridazine: Potential use for initial therapy of freshly diagnosed tuberculosis. J. Antimicrob. Chemother. 1996, 38, 1049-1053. [CrossRef]

96. Bettencourt, M.V.; Bosne-David, S.; Amaral, L. Comparative in vitro activity of phenothiazines against multidrug-resistant Mycobacterium tuberculosis. Int. J. Antimicrob. Agents 2000, 16, 69-71. [CrossRef]

97. Ratnakar, P.; Murthy, P.S. Antitubercular activity of trifluoperazine, a calmodulin antagonist. FEMS Microbiol. Lett. 1992, 76, 73-76. [CrossRef] [PubMed]

98. Gadre, D.V.; Talwar, V. In vitro susceptibility testing of Mycobacterium tuberculosis strains to trifluoperazine. J. Chemother. Florence Italy 1999, 11, 203-206. [CrossRef] [PubMed]

99. Amaral, L.; Kristiansen, J.E.; Viveiros, M.; Atouguia, J. Activity of phenothiazines against antibiotic-resistant Mycobacterium tuberculosis: A review supporting further studies that may elucidate the potential use of thioridazine as anti-tuberculosis therapy. J. Antimicrob. Chemother. 2001, 47, 505-511. [CrossRef] [PubMed]

100. Amaral, L.; Viveiros, M. Thioridazine: A non-antibiotic drug highly effective, in combination with first line anti-tuberculosis drugs, against any form of antibiotic resistance of mycobacterium tuberculosis due to its multi-mechanisms of action. Antibiotics 2017, 6, 3. [CrossRef]

101. Crowle, A.J.; Douvas, G.S.; May, M.H. Chlorpromazine: A drug potentially useful for treating mycobacterial infections. Chemotherapy 1992, 38, 410-419. [CrossRef]

102. Salie, S.; Hsu, N.-J.; Semenya, D.; Jardine, A.; Jacobs, M. Novel non-neuroleptic phenothiazines inhibit Mycobacterium tuberculosis replication. J. Antimicrob. Chemother. 2014, 69, 1551-1558. [CrossRef]

103. He, C.-X.; Meng, H.; Zhang, X.; Cui, H.-Q.; Yin, D.-L. Synthesis and bio-evaluation of phenothiazine derivatives as new anti-tuberculosis agents. Chin. Chem. Lett. 2015, 26, 951-954. [CrossRef]

104. Jardine, M.A.; Jacobs, M. Phenothiazine Derivatives and Their Use against Tuberculosis. WO2014080378A1, 30 May 2014.

105. Trivedi, A.R.; Siddiqui, A.B.; Shah, V.H. Design, synthesis, characterization and antitubercular activity of some 2-heterocycle-substituted phenothiazines. Arkivoc 2008, 2008, 210-217.

106. Shirude, P.S.; Paul, B.; Roy Choudhury, N.; Kedari, C.; Bandodkar, B.; Ugarkar, B.G. Quinolinyl Pyrimidines: Potent Inhibitors of NDH-2 as a Novel Class of Anti-TB Agents. ACS Med. Chem. Lett. 2012, 3, 736-740. [CrossRef]

107. Heikal, A.; Hards, K.; Cheung, C.-Y.; Menorca, A.; Timmer, M.S.M.; Stocker, B.L.; Cook, G.M. Activation of type II NADH dehydrogenase by quinolinequinones mediates antitubercular cell death. J. Antimicrob. Chemother. 2016, 71, 2840-2847. [CrossRef] 
108. Bringmann, G.; Reichert, Y.; Kane, V.V. The total synthesis of streptonigrin and related antitumor antibiotic natural products. Tetrahedron 2004, 60, 3539-3574. [CrossRef]

109. Colucci, M.A.; Moody, C.J.; Couch, G.D. Natural and synthetic quinones and their reduction by the quinone reductase enzyme NQO1: From synthetic organic chemistry to compounds with anticancer potential. Org. Biomol. Chem. 2008, 6, 637-656. [CrossRef] [PubMed]

110. Pearce, A.N.; Chia, E.W.; Berridge, M.V.; Clark, G.R.; Harper, J.L.; Larsen, L.; Maas, E.W.; Page, M.J.; Perry, N.B.; Webb, V.L.; et al. Anti-inflammatory thiazine alkaloids isolated from the New Zealand ascidian Aplidium sp.: Inhibitors of the neutrophil respiratory burst in a model of gouty arthritis. J. Nat. Prod. 2007, 70, 936-940. [CrossRef] [PubMed]

111. Mulchin, B.J.; Newton, C.G.; Baty, J.W.; Grasso, C.H.; Martin, W.J.; Walton, M.C.; Dangerfield, E.M.; Plunkett, C.H.; Berridge, M.V.; Harper, J.L.; et al. The anti-cancer, anti-inflammatory and tuberculostatic activities of a series of 6,7-substituted-5,8-quinolinequinones. Bioorg. Med. Chem. 2010, 18, 3238-3251. [CrossRef]

112. Santoso, K.T.; Menorca, A.; Cheung, C.-Y.; Cook, G.M.; Stocker, B.L.; Timmer, M.S.M. The synthesis and evaluation of quinolinequinones as anti-mycobacterial agents. Bioorg. Med. Chem. 2019, 27, 3532-3545. [CrossRef]

113. Barry, V.C.; Belton, J.G.; Conalty, M.L.; Denneny, J.M.; Edward, D.W.; O'sullivan, J.F.; Twomey, D.; Winder, F. A new series of phenazines (rimino-compounds) with high antituberculosis activity. Nature 1957, 179, 1013-1015. [CrossRef]

114. Zhang, D.; Liu, Y.; Zhang, C.; Zhang, H.; Wang, B.; Xu, J.; Fu, L.; Yin, D.; Cooper, C.B.; Ma, Z.; et al. Synthesis and biological evaluation of novel 2-methoxypyridylamino-substituted riminophenazine derivatives as antituberculosis agents. Molecules 2014, 19, 4380-4394. [CrossRef]

115. Fang, M.; Toogood, R.D.; Macova, A.; Ho, K.; Franzblau, S.G.; McNeil, M.R.; Sanders, D.A.R.; Palmer, D.R.J. Succinylphosphonate esters are competitive inhibitors of mend that show active-site discrimination between homologous $\alpha$-ketoglutarate-decarboxylating enzymes. Biochemistry 2010, 49, 2672-2679. [CrossRef]

116. Kurosu, M.; Narayanasamy, P.; Biswas, K.; Dhiman, R.; Crick, D.C. Discovery of 1,4-dihydroxy-2-naphthoate [corrected] prenyltransferase inhibitors: New drug leads for multidrug-resistant gram-positive pathogens. J. Med. Chem. 2007, 50, 3973-3975. [CrossRef]

117. Berube, B.J.; Russell, D.; Castro, L.; Choi, S.; Narayanasamy, P.; Parish, T. Novel mena inhibitors are bactericidal against mycobacterium tuberculosis and synergize with electron transport chain inhibitors. Antimicrob. Agents Chemother. 2019, 63, e02661-18. [CrossRef]

118. Benkovic, S.J.; Baker, S.J.; Alley, M.R.K.; Woo, Y.-H.; Zhang, Y.-K.; Akama, T.; Mao, W.; Baboval, J.; Rajagopalan, P.T.R.; Wall, M.; et al. Identification of borinic esters as inhibitors of bacterial cell growth and bacterial methyltransferases, CcrM and MenH. J. Med. Chem. 2005, 48, 7468-7476. [CrossRef] [PubMed]

119. Jirgis, E.N.M.; Bashiri, G.; Bulloch, E.M.M.; Johnston, J.M.; Baker, E.N. Structural views along the mycobacterium tuberculosis MenD reaction pathway illuminate key aspects of thiamin diphosphate-dependent enzyme mechanisms. Structure 2016, 24, 1167-1177. [CrossRef] [PubMed]

120. Lu, X.; Zhou, R.; Sharma, I.; Li, X.; Kumar, G.; Swaminathan, S.; Tonge, P.J.; Tan, D.S. Stable analogues of OSB-AMP: Potent inhibitors of MenE, the o-succinylbenzoate-CoA synthetase from bacterial menaquinone biosynthesis. Chembiochem Eur. J. Chem. Biol. 2012, 13, 129-136. [CrossRef] [PubMed]

121. Kitagawa, W.; Tamura, T. A Quinoline Antibiotic from Rhodococcus erythropolis JCM 6824. J. Antibiot. (Tokyo) 2008, 61, 680-682. [CrossRef]

122. Dhiman, R.K.; Pujari, V.; Kincaid, J.M.; Ikeh, M.A.; Parish, T.; Crick, D.C. Characterization of MenA (isoprenyl diphosphate:1,4-dihydroxy-2-naphthoate isoprenyltransferase) from Mycobacterium tuberculosis. PLoS ONE 2019, 14, e0214958. [CrossRef]

123. Choi, S.; Frandsen, J.; Narayanasamy, P. Novel long-chain compounds with both immunomodulatory and MenA inhibitory activities against Staphylococcus aureus and its biofilm. Sci. Rep. 2017, 7, 40077. [CrossRef]

124. Choi, S.; Larson, M.A.; Hinrichs, S.H.; Bartling, A.M.; Frandsen, J.; Narayanasamy, P. Discovery of bicyclic inhibitors against menaquinone biosynthesis. Future Med. Chem. 2016, 8, 11-16. [CrossRef]

125. Ballell, L.; Bates, R.H.; Young, R.J.; Alvarez-Gomez, D.; Alvarez-Ruiz, E.; Barroso, V.; Blanco, D.; Crespo, B.; Escribano, J.; González, R.; et al. Fueling open-source drug discovery: 177 small-molecule leads against tuberculosis. ChemMedChem 2013, 8, 313-321. [CrossRef] 
126. Moraski, G.C.; Deboosère, N.; Marshall, K.L.; Weaver, H.A.; Vandeputte, A.; Hastings, C.; Woolhiser, L.; Lenaerts, A.J.; Brodin, P.; Miller, M.J. Intracellular and in vivo evaluation of imidazo[2,1-b]thiazole-5-carboxamide anti-tuberculosis compounds. PLoS ONE 2020, 15, e0227224. [CrossRef]

127. Tantry, S.J.; Markad, S.D.; Shinde, V.; Bhat, J.; Balakrishnan, G.; Gupta, A.K.; Ambady, A.; Raichurkar, A.; Kedari, C.; Sharma, S.; et al. Discovery of Imidazo[1,2-a]pyridine ethers and squaramides as selective and potent inhibitors of mycobacterial adenosine triphosphate (ATP) synthesis. J. Med. Chem. 2017, 60, 1379-1399. [CrossRef]

128. Lu, X.; Williams, Z.; Hards, K.; Tang, J.; Cheung, C.-Y.; Aung, H.L.; Wang, B.; Liu, Z.; Hu, X.; Lenaerts, A.; et al. Pyrazolo[1,5- a]pyridine inhibitor of the respiratory cytochrome bcc complex for the treatment of drug-resistant tuberculosis. ACS Infect. Dis. 2019, 5, 239-249. [CrossRef] [PubMed]

129. Rybniker, J.; Vocat, A.; Sala, C.; Busso, P.; Pojer, F.; Benjak, A.; Cole, S.T. Lansoprazole is an antituberculous prodrug targeting cytochrome bc1. Nat. Commun. 2015, 6, 7659. [CrossRef] [PubMed]

130. Chandrasekera, N.S.; Berube, B.J.; Shetye, G.; Chettiar, S.; O'Malley, T.; Manning, A.; Flint, L.; Awasthi, D.; Ioerger, T.R.; Sacchettini, J.; et al. Improved phenoxyalkylbenzimidazoles with activity against Mycobacterium tuberculosis appear to target QcrB. ACS Infect. Dis. 2017, 3, 898-916. [CrossRef] [PubMed]

131. van der Westhuyzen, R.; Winks, S.; Wilson, C.R.; Boyle, G.A.; Gessner, R.K.; Soares de Melo, C.; Taylor, D.; de Kock, C.; Njoroge, M.; Brunschwig, C.; et al. Pyrrolo[3,4-c]pyridine-1,3(2H)-diones: A novel antimycobacterial class targeting mycobacterial respiration. J. Med. Chem. 2015, 58, 9371-9381. [CrossRef] [PubMed]

132. Pissinate, K.; Villela, A.D.; Rodrigues-Junior, V.; Giacobbo, B.C.; Grams, E.S.; Abbadi, B.L.; Trindade, R.V.; Roesler Nery, L.; Bonan, C.D.; Back, D.F.; et al. 2-(Quinolin-4-yloxy)acetamides are active against drug-susceptible and drug-resistant mycobacterium tuberculosis strains. ACS Med. Chem. Lett. 2016, 7, 235-239. [CrossRef] [PubMed]

133. Giacobbo, B.C.; Pissinate, K.; Rodrigues-Junior, V.; Villela, A.D.; Grams, E.S.; Abbadi, B.L.; Subtil, F.T.; Sperotto, N.; Trindade, R.V.; Back, D.F.; et al. New insights into the SAR and drug combination synergy of 2-(quinolin-4-yloxy)acetamides against Mycobacterium tuberculosis. Eur. J. Med. Chem. 2017, 126, 491-501. [CrossRef]

134. Cleghorn, L.A.T.; Ray, P.C.; Odingo, J.; Kumar, A.; Wescott, H.; Korkegian, A.; Masquelin, T.; Lopez Moure, A.; Wilson, C.; Davis, S.; et al. Identification of morpholino thiophenes as novel mycobacterium tuberculosis inhibitors, targeting QcrB. J. Med. Chem. 2018, 61, 6592-6608. [CrossRef]

135. Harrison, G.A.; Bridwell, A.E.M.; Singh, M.; Jayaraman, K.; Weiss, L.A.; Kinsella, R.L.; Aneke, J.S.; Flentie, K.; Schene, M.E.; Gaggioli, M.; et al. Identification of 4-Amino-Thieno[2,3-d]Pyrimidines as QcrB Inhibitors in Mycobacterium tuberculosis. mSphere 2019, 4, e00606-19. [CrossRef]

136. Meunier, B.; Madgwick, S.A.; Reil, E.; Oettmeier, W.; Rich, P.R. New inhibitors of the quinol oxidation sites of bacterial cytochromes bo and bd. Biochemistry 1995, 34, 1076-1083. [CrossRef]

137. Moraski, G.C.; Markley, L.D.; Hipskind, P.A.; Boshoff, H.; Cho, S.; Franzblau, S.G.; Miller, M.J. Advent of Imidazo[1,2-a]pyridine-3-carboxamides with potent multi- and extended drug resistant antituberculosis activity. ACS Med. Chem. Lett. 2011, 2, 466-470. [CrossRef]

138. Abrahams, K.A.; Cox, J.A.G.; Spivey, V.L.; Loman, N.J.; Pallen, M.J.; Constantinidou, C.; Fernández, R.; Alemparte, C.; Remuiñán, M.J.; Barros, D.; et al. Identification of novel imidazo[1,2-a]pyridine inhibitors targeting M. tuberculosis QcrB. PLoS ONE 2012, 7, e52951. [CrossRef] [PubMed]

139. Mak, P.A.; Rao, S.P.S.; Ping Tan, M.; Lin, X.; Chyba, J.; Tay, J.; Ng, S.H.; Tan, B.H.; Cherian, J.; Duraiswamy, J.; et al. A high-throughput screen to identify inhibitors of atp homeostasis in non-replicating mycobacterium tuberculosis. ACS Chem. Biol. 2012, 7, 1190-1197. [CrossRef]

140. Moraski, G.C.; Markley, L.D.; Cramer, J.; Hipskind, P.A.; Boshoff, H.; Bailey, M.; Alling, T.; Ollinger, J.; Parish, T.; Miller, M.J. Advancement of Imidazo[1,2-a]pyridines with improved pharmacokinetics and nanomolar activity against mycobacterium tuberculosis. ACS Med. Chem. Lett. 2013, 4, 675-679. [CrossRef] [PubMed]

141. Moraski, G.C.; Oliver, A.G.; Markley, L.D.; Cho, S.; Franzblau, S.G.; Miller, M.J. Scaffold-switching: An exploration of 5,6-fused bicyclic heteroaromatics systems to afford antituberculosis activity akin to the imidazo[1,2-a]pyridine-3-carboxylates. Bioorg. Med. Chem. Lett. 2014, 24, 3493-3498. [CrossRef] [PubMed] 
142. Kang, S.; Kim, R.Y.; Seo, M.J.; Lee, S.; Kim, Y.M.; Seo, M.; Seo, J.J.; Ko, Y.; Choi, I.; Jang, J.; et al. Lead optimization of a novel series of imidazo[1,2-a]pyridine amides leading to a clinical candidate (Q203) as a multi- and extensively-drug-resistant anti-tuberculosis agent. J. Med. Chem. 2014, 57, 5293-5305. [CrossRef] [PubMed]

143. Moraski, G.C.; Seeger, N.; Miller, P.A.; Oliver, A.G.; Boshoff, H.I.; Cho, S.; Mulugeta, S.; Anderson, J.R.; Franzblau, S.G.; Miller, M.J. Arrival of Imidazo[2,1-b]thiazole-5-carboxamides: Potent anti-tuberculosis agents that target QcrB. ACS Infect. Dis. 2016, 2, 393-398. [CrossRef] [PubMed]

144. Telacebec (Q203) | Working Group for New TB Drugs. Available online: https://www.newtbdrugs.org/ pipeline/compound/telacebec-q203 (accessed on 3 February 2020).

145. Bouvier, G.; Simenel, C.; Jang, J.; Kalia, N.P.; Choi, I.; Nilges, M.; Pethe, K.; Izadi-Pruneyre, N. Target engagement and binding mode of an antituberculosis drug to its bacterial target deciphered in whole living cells by NMR. Biochemistry 2019, 58, 526-533. [CrossRef]

146. Moosa, A.; Lamprecht, D.A.; Arora, K.; Barry, C.E.; Boshoff, H.I.M.; Ioerger, T.R.; Steyn, A.J.C.; Mizrahi, V.; Warner, D.F. Susceptibility of mycobacterium tuberculosis cytochrome bd oxidase mutants to compounds targeting the terminal respiratory oxidase, cytochrome c. Antimicrob. Agents Chemother. 2017, 61, e01338-17. [CrossRef]

147. Scherr, N.; Bieri, R.; Thomas, S.S.; Chauffour, A.; Kalia, N.P.; Schneide, P.; Ruf, M.-T.; Lamelas, A.; Manimekalai, M.S.S.; Grüber, G.; et al. Targeting the Mycobacterium ulcerans cytochrome bc1:aa3 for the treatment of Buruli ulcer. Nat. Commun. 2018, 9, 5370. [CrossRef]

148. Tang, J.; Wang, B.; Wu, T.; Wan, J.; Tu, Z.; Njire, M.; Wan, B.; Franzblauc, S.G.; Zhang, T.; Lu, X.; et al. Design, synthesis, and biological evaluation of Pyrazolo[1,5-a]pyridine-3-carboxamides as novel antitubercular agents. ACS Med. Chem. Lett. 2015, 6, 814-818. [CrossRef]

149. Lu, X.; Tang, J.; Cui, S.; Wan, B.; Franzblauc, S.G.; Zhang, T.; Zhang, X.; Ding, K. Pyrazolo[1,5-a]pyridine-3carboxamide hybrids: Design, synthesis and evaluation of anti-tubercular activity. Eur. J. Med. Chem. 2017, 125, 41-48. [CrossRef] [PubMed]

150. Lee, B.S.; Kalia, N.P.; Jin, X.E.F.; Hasenoehrl, E.J.; Berney, M.; Pethe, K. Inhibitors of energy metabolism interfere with antibiotic-induced death in mycobacteria. J. Biol. Chem. 2019, 294, 1936-1943. [CrossRef] [PubMed]

151. Mdanda, S.; Baijnath, S.; Shobo, A.; Singh, S.D.; Maguire, G.E.M.; Kruger, H.G.; Arvidsson, P.I.; Naicker, T.; Govender, T. Lansoprazole-sulfide, pharmacokinetics of this promising anti-tuberculous agent. Biomed. Chromatogr. 2017, 31, e4035. [CrossRef] [PubMed]

152. Yates, T.A.; Tomlinson, L.A.; Bhaskaran, K.; Langan, S.; Thomas, S.; Smeeth, L.; Douglas, I.J. Lansoprazole use and tuberculosis incidence in the United Kingdom Clinical Practice Research Datalink: A population based cohort. PLoS Med. 2017, 14, e1002457. [CrossRef]

153. Chandrasekera, N.S.; Alling, T.; Bailey, M.A.; Files, M.; Early, J.V.; Ollinger, J.; Ovechkina, Y.; Masquelin, T.; Desai, P.V.; Cramer, J.W.; et al. Identification of phenoxyalkylbenzimidazoles with antitubercular activity. J. Med. Chem. 2015, 58, 7273-7285. [CrossRef]

154. Pitta, E.; Rogacki, M.K.; Balabon, O.; Huss, S.; Cunningham, F.; Lopez-Roman, E.M.; Joossens, J.; Augustyns, K.; Ballell, L.; Bates, R.H.; et al. Searching for New Leads for Tuberculosis: Design, Synthesis, and Biological Evaluation of Novel 2-Quinolin-4-yloxyacetamides. J. Med. Chem. 2016, 59, 6709-6728. [CrossRef]

155. Phummarin, N.; Boshoff, H.I.; Tsang, P.S.; Dalton, J.; Wiles, S.; Barry 3rd, C.E.; Copp, B.R. SAR and identification of 2-(quinolin-4-yloxy)acetamides as Mycobacterium tuberculosis cytochrome bc 1 inhibitors. Medchemcomm 2016, 7, 2122-2127. [CrossRef]

156. Subtil, F.T.; Villela, A.D.; Abbadi, B.L.; Rodrigues-Junior, V.S.; Bizarro, C.V.; Timmers, L.F.S.M.; de Souza, O.N.; Pissinate, K.; Machado, P.; López-Gavín, A.; et al. Activity of 2-(quinolin-4-yloxy)acetamides in Mycobacterium tuberculosis clinical isolates and identification of their molecular target by whole-genome sequencing. Int. J. Antimicrob. Agents 2018, 51, 378-384. [CrossRef]

157. Berry, E.A.; Guergova-Kuras, M.; Huang, L.S.; Crofts, A.R. Structure and function of cytochrome bc complexes. Annu. Rev. Biochem. 2000, 69, 1005-1075. [CrossRef]

158. Lamprecht, D.A.; Finin, P.M.; Rahman, M.A.; Cumming, B.M.; Russell, S.L.; Jonnala, S.R.; Adamson, J.H.; Steyn, A.J.C. Turning the respiratory flexibility of Mycobacterium tuberculosis against itself. Nat. Commun. 2016, 7, 12393. [CrossRef] 
159. Lu, P.; Heineke, M.H.; Koul, A.; Andries, K.; Cook, G.M.; Lill, H.; van Spanning, R.; Bald, D. The cytochrome bd-type quinol oxidase is important for survival of Mycobacterium smegmatis under peroxide and antibiotic-induced stress. Sci. Rep. 2015, 5, 10333. [CrossRef] [PubMed]

160. Lu, P.; Asseri, A.H.; Kremer, M.; Maaskant, J.; Ummels, R.; Lill, H.; Bald, D. The anti-mycobacterial activity of the cytochrome bcc inhibitor Q203 can be enhanced by small-molecule inhibition of cytochrome bd. Sci. Rep. 2018, 8, 2625. [CrossRef] [PubMed]

161. Flentie, K.; Harrison, G.A.; Tükenmez, H.; Livny, J.; Good, J.A.D.; Sarkar, S.; Zhu, D.X.; Kinsella, R.L.; Weiss, L.A.; Solomon, S.D.; et al. Chemical disarming of isoniazid resistance in Mycobacterium tuberculosis. Proc. Natl. Acad. Sci. USA 2019, 116, 10510-10517. [CrossRef] [PubMed]

162. Tran, S.L.; Cook, G.M. The F1Fo-ATP synthase of Mycobacterium smegmatis is essential for growth. J. Bacteriol. 2005, 187, 5023-5028. [CrossRef]

163. Koul, A.; Dendouga, N.; Vergauwen, K.; Molenberghs, B.; Vranckx, L.; Willebrords, R.; Ristic, Z.; Lill, H.; Dorange, I.; Guillemont, J.; et al. Diarylquinolines target subunit c of mycobacterial ATP synthase. Nat. Chem. Biol. 2007, 3, 323-324. [CrossRef]

164. Haagsma, A.C.; Podasca, I.; Koul, A.; Andries, K.; Guillemont, J.; Lill, H.; Bald, D. Probing the interaction of the diarylquinoline TMC207 with its target mycobacterial ATP synthase. PLoS ONE 2011, 6, e23575. [CrossRef]

165. Nesci, S.; Trombetti, F.; Algieri, C.; Pagliarani, A. A therapeutic role for the F1FO-ATP synthase. SLAS Discov. Adv. Life Sci. R D 2019, 24, 893-903. [CrossRef]

166. Preiss, L.; Langer, J.D.; Yildiz, Ö.; Eckhardt-Strelau, L.; Guillemont, J.E.G.; Koul, A.; Meier, T. Structure of the mycobacterial ATP synthase Fo rotor ring in complex with the anti-TB drug bedaquiline. Sci. Adv. 2015, 1, e1500106. [CrossRef]

167. Hards, K.; McMillan, D.G.G.; Schurig-Briccio, L.A.; Gennis, R.B.; Lill, H.; Bald, D.; Cook, G.M. Ionophoric effects of the antitubercular drug bedaquiline. Proc. Natl. Acad. Sci. USA 2018, 115, 7326-7331. [CrossRef]

168. Hartkoorn, R.C.; Uplekar, S.; Cole, S.T. Cross-resistance between clofazimine and bedaquiline through upregulation of MmpL5 in Mycobacterium tuberculosis. Antimicrob. Agents Chemother. 2014, 58, 2979-2981. [CrossRef]

169. Almeida, D.; Ioerger, T.; Tyagi, S.; Li, S.-Y.; Mdluli, K.; Andries, K.; Grosset, J.; Sacchettini, J.; Nuermberger, E. Mutations in pepQ confer low-level resistance to bedaquiline and clofazimine in mycobacterium tuberculosis. Antimicrob. Agents Chemother. 2016, 60, 4590-4599. [CrossRef] [PubMed]

170. Xu, J.; Wang, B.; Hu, M.; Huo, F.; Guo, S.; Jing, W.; Nuermberger, E.; Lu, Y. Primary clofazimine and bedaquiline resistance among isolates from patients with multidrug-resistant tuberculosis. Antimicrob. Agents Chemother. 2017, 61, e00239-17. [CrossRef] [PubMed]

171. Ghajavand,H.; Kargarpour Kamakoli, M.; Khanipour, S.; Pourazar Dizaji, S.; Masoumi, M.; Rahimi Jamnani, F.; Fateh, A.; Siadat, S.D.; Vaziri, F. High prevalence of bedaquiline resistance in treatment-naive tuberculosis patients and verapamil effectiveness. Antimicrob. Agents Chemother. 2019, 63, e02530-18. [CrossRef] [PubMed]

172. Zimenkov, D.V.; Nosova, E.Y.; Kulagina, E.V.; Antonova, O.V.; Arslanbaeva, L.R.; Isakova, A.I.; Krylova, L.Y.; Peretokina, I.V.; Makarova, M.V.; Safonova, S.G.; et al. Examination of bedaquiline- and linezolid-resistant Mycobacterium tuberculosis isolates from the Moscow region. J. Antimicrob. Chemother. 2017, 72, 1901-1906. [CrossRef] [PubMed]

173. Villellas, C.; Coeck, N.; Meehan, C.J.; Lounis, N.; de Jong, B.; Rigouts, L.; Andries, K. Unexpected high prevalence of resistance-associated Rv0678 variants in MDR-TB patients without documented prior use of clofazimine or bedaquiline. J. Antimicrob. Chemother. 2017, 72, 684-690. [PubMed]

174. Guglielmetti, L.; Tiberi, S.; Burman, M.; Kunst, H.; Wejse, C.; Togonidze, T.; Bothamley, G.; Lange, C. QT prolongation and cardiac toxicity of new tuberculosis drugs in Europe: A tuberculosis network European trialsgroup (TBnet) study. Eur. Respir. J. 2018, 52, 1800537. [CrossRef]

175. Tong, A.S.T.; Choi, P.J.; Blaser, A.; Sutherland, H.S.; Tsang, S.K.Y.; Guillemont, J.; Motte, M.; Cooper, C.B.; Andries, K.; Van den Broeck, W.; et al. 6-Cyano analogues of bedaquiline as less lipophilic and potentially safer diarylquinolines for tuberculosis. ACS Med. Chem. Lett. 2017, 8, 1019-1024. [CrossRef]

176. Choi, P.J.; Sutherland, H.S.; Tong, A.S.T.; Blaser, A.; Franzblau, S.G.; Cooper, C.B.; Lotlikar, M.U.; Upton, A.M.; Guillemont, J.; Motte, M.; et al. Synthesis and evaluation of analogues of the tuberculosis drug bedaquiline containing heterocyclic B-ring units. Bioorg. Med. Chem. Lett. 2017, 27, 5190-5196. [CrossRef] 
177. Sutherland, H.S.; Tong, A.S.T.; Choi, P.J.; Conole, D.; Blaser, A.; Franzblau, S.G.; Cooper, C.B.; Upton, A.M.; Lotlikar, M.U.; Denny, W.A.; et al. Structure-activity relationships for analogs of the tuberculosis drug bedaquiline with the naphthalene unit replaced by bicyclic heterocycles. Bioorg. Med. Chem. 2018, 26, 1797-1809. [CrossRef]

178. Blaser, A.; Sutherland, H.S.; Tong, A.S.T.; Choi, P.J.; Conole, D.; Franzblau, S.G.; Cooper, C.B.; Upton, A.M.; Lotlikar, M.; Denny, W.A.; et al. Structure-activity relationships for unit C pyridyl analogues of the tuberculosis drug bedaquiline. Bioorg. Med. Chem. 2019, 27, 1283-1291. [CrossRef]

179. Sutherland, H.S.; Tong, A.S.T.; Choi, P.J.; Blaser, A.; Conole, D.; Franzblau, S.G.; Lotlikar, M.U.; Cooper, C.B.; Upton, A.M.; Denny, W.A.; et al. 3,5-Dialkoxypyridine analogues of bedaquiline are potent antituberculosis agents with minimal inhibition of the hERG channel. Bioorg. Med. Chem. 2019, 27, 1292-1307. [CrossRef]

180. Sarathy, J.P.; Ragunathan, P.; Shin, J.; Cooper, C.B.; Upton, A.M.; Grüber, G.; Dick, T. TBAJ-876 retains bedaquiline's activity against subunits $\mathrm{c}$ and $\varepsilon$ of mycobacterium tuberculosis F-ATP synthase. Antimicrob. Agents Chemother. 2019, 63, e01191-19. [CrossRef] [PubMed]

181. Kumar, S.; Mehra, R.; Sharma, S.; Bokolia, N.P.; Raina, D.; Nargotra, A.; Singh, P.P.; Khan, I.A. Screening of antitubercular compound library identifies novel ATP synthase inhibitors of mycobacterium tuberculosis. Tuberc. Edinb. Scotl. 2018, 108, 56-63. [CrossRef] [PubMed]

182. Lu, P.; Haagsma, A.C.; Pham, H.; Maaskant, J.J.; Mol, S.; Lill, H.; Bald, D. Pyrazinoic acid decreases the proton motive force, respiratory ATP synthesis activity, and cellular ATP levels. Antimicrob. Agents Chemother. 2011, 55, 5354-5357. [CrossRef] [PubMed]

183. Feng, X.; Zhu, W.; Schurig-Briccio, L.A.; Lindert, S.; Shoen, C.; Hitchings, R.; Li, J.; Wang, Y.; Baig, N.; Zhou, T.; et al. Antiinfectives targeting enzymes and the proton motive force. Proc. Natl. Acad. Sci. USA 2015, 112, E7073-E7082. [CrossRef] [PubMed]

184. Jeon, A.B.; Ackart, D.F.; Li, W.; Jackson, M.; Melander, R.J.; Melander, C.; Abramovitch, R.B.; Chicco, A.J.; Basaraba, R.J.; Obregón-Henao, A. 2-aminoimidazoles collapse mycobacterial proton motive force and block the electron transport chain. Sci. Rep. 2019, 9, 1513. [CrossRef] [PubMed]

185. Jeon, A.B.; Obregón-Henao, A.; Ackart, D.F.; Podell, B.K.; Belardinelli, J.M.; Jackson, M.; Nguyen, T.V.; Blackledge, M.S.; Melander, R.J.; Melander, C.; et al. 2-aminoimidazoles potentiate B-lactam antimicrobial activity against Mycobacterium tuberculosis by reducing B-lactamase secretion and increasing cell envelope permeability. PLoS ONE 2017, 12, e0180925. [CrossRef]

186. Protopopova, M.; Hanrahan, C.; Nikonenko, B.; Samala, R.; Chen, P.; Gearhart, J.; Einck, L.; Nacy, C.A. Identification of a new antitubercular drug candidate, SQ109, from a combinatorial library of 1,2-ethylenediamines. J. Antimicrob. Chemother. 2005, 56, 968-974. [CrossRef]

187. Li, K.; Schurig-Briccio, L.A.; Feng, X.; Upadhyay, A.; Pujari, V.; Lechartier, B.; Fontes, F.L.; Yang, H.; Rao, G.; $\mathrm{Zhu}, \mathrm{W}$; et al. Multitarget drug discovery for tuberculosis and other infectious diseases. J. Med. Chem. 2014, 57, 3126-3139. [CrossRef]

188. Zhang, Y.; Wade, M.M.; Scorpio, A.; Zhang, H.; Sun, Z. Mode of action of pyrazinamide: Disruption of Mycobacterium tuberculosis membrane transport and energetics by pyrazinoic acid. J. Antimicrob. Chemother. 2003, 52, 790-795. [CrossRef]

189. Yang, C.-S.; Yuk, J.-M.; Jo, E.-K. The role of nitric oxide in mycobacterial infections. Immune Netw. 2009, 9, 46-52. [CrossRef]

190. Manjunatha, U.; Boshoff, H.I.; Barry, C.E. The mechanism of action of PA-824. Commun. Integr. Biol. 2009, 2, 215-218. [CrossRef] [PubMed]

191. Stover, C.K.; Warrener, P.; VanDevanter, D.R.; Sherman, D.R.; Arain, T.M.; Langhorne, M.H.; Anderson, S.W.; Towell, J.A.; Yuan, Y.; McMurray, D.N.; et al. A small-molecule nitroimidazopyran drug candidate for the treatment of tuberculosis. Nature 2000, 405, 962-966. [CrossRef]

192. Matsumoto, M.; Hashizume, H.; Tomishige, T.; Kawasaki, M.; Tsubouchi, H.; Sasaki, H.; Shimokawa, Y.; Komatsu, M. OPC-67683, a nitro-dihydro-imidazooxazole derivative with promising action against tuberculosis in vitro and in mice. PLoS Med. 2006, 3, e466. [CrossRef]

193. Van den Bossche, A.; Varet, H.; Sury, A.; Sismeiro, O.; Legendre, R.; Coppee, J.-Y.; Mathys, V.; Ceyssens, P.-J. Transcriptional profiling of a laboratory and clinical Mycobacterium tuberculosis strain suggests respiratory poisoning upon exposure to delamanid. Tuberc. Edinb. Scotl. 2019, 117, 18-23. [CrossRef] [PubMed]

194. Developing New TB Regimens. Available online: https://www.tballiance.org/rd/developing-new-regimens (accessed on 23 December 2019). 
195. Berube, B.J.; Parish, T. Combinations of respiratory chain inhibitors have enhanced bactericidal activity against mycobacterium tuberculosis. Antimicrob. Agents Chemother. 2018, 62, e01677-17. [CrossRef] [PubMed]

196. Moraski, G.C.; Cheng, Y.; Cho, S.; Cramer, J.W.; Godfrey, A.; Masquelin, T.; Franzblau, S.G.; Miller, M.J.; Schorey, J. Imidazo[1,2-a]Pyridine-3-Carboxamides are active antimicrobial agents against mycobacterium avium infection in vivo. Antimicrob. Agents Chemother. 2016, 60, 5018-5022. [CrossRef]

197. Heinrich, N.; Dawson, R.; du Bois, J.; Narunsky, K.; Horwith, G.; Phipps, A.J.; Nacy, C.A.; Aarnoutse, R.E.; Boeree, M.J.; Gillespie, S.H.; et al. Early phase evaluation of SQ109 alone and in combination with rifampicin in pulmonary TB patients. J. Antimicrob. Chemother. 2015, 70, 1558-1566. [CrossRef]

198. Zhang, Y.; Zhu, H.; Fu, L.; Wang, B.; Guo, S.; Chen, X.; Liu, Z.; Huang, H.; Yang, T.; Lu, Y. Identifying regimens containing TBI-166, a new drug candidate against mycobacterium tuberculosis in vitro and in vivo. Antimicrob. Agents Chemother. 2019, 63, e02496-18. [CrossRef]

199. Converse, P.J.; Almeida, D.V.; Tyagi, S.; Xu, J.; Nuermberger, E.L. Shortening buruli ulcer treatment with combination therapy targeting the respiratory chain and exploiting mycobacterium ulcerans gene decay. Antimicrob. Agents Chemother. 2019, 63, e00426-19. [CrossRef]

(C) 2020 by the authors. Licensee MDPI, Basel, Switzerland. This article is an open access article distributed under the terms and conditions of the Creative Commons Attribution (CC BY) license (http://creativecommons.org/licenses/by/4.0/). 